\title{
Full title: Confirmation of interpersonal expectations is intrinsically rewarding
}

\section{Short title: Confirmation of social expectations is rewarding}

Niv Reggev*1,2,3 Anoushka Chowdhary $^{1}$, and Jason P. Mitchell ${ }^{1}$

${ }^{1}$ Department of Psychology, Harvard University, 33 Kirkland St, Cambridge, MA, US, 0218

${ }^{2}$ Department of Psychology and ${ }^{3}$ Zlotowski Center for Neuroscience, Ben-Gurion University of the Negev, P.O. Box 653, Be'er-Sheva, Israel, 84105

ORCiD identifiers:

Niv Reggev: 0000-0002-5734-7457

Corresponding author:

Niv Reggev, Department of Psychology, Ben Gurion University of the Negev, P.O. Box 653,

Be'er-Sheva, Israel, 84105

Phone number: +972-8-67472030

Email address: reggevn@,bgu.ac.il

This article is a preprint, not yet published in a peer-reviewed journal. We welcome any comments or feedback - please send these to the corresponding author 
REWARDING EXPECTATION-CONFIRMATION

\begin{abstract}
2 People want to interact successfully with other individuals, and they invest significant efforts

3 in attempting to do so. Decades of research have demonstrated that to simplify the dauntingly

4 complex task of interpersonal communication, perceivers use stereotypes and other sources of

5 prior knowledge to predict the responses of individuals in their environment. Here, we show that

6 these top-down expectations can also shape the subjective value of expectation-consistent and

7 expectation-violating targets. Specifically, in two neuroimaging experiments $(n=58)$, we

8 observed increased activation in brain regions associated with reward processing — including the

9 nucleus accumbens - when perceivers observed information consistent with their social

10 expectations. In two additional behavioral experiments $(n=704)$, we observed that perceivers

11 were willing to forgo money to encounter an expectation-consistent target and avoid an

12 expectation-violating target. Together, these findings suggest that perceivers value having their

13 social expectations confirmed, much like food or monetary rewards.
\end{abstract}

14

15 Keywords: Stereotypes, Expectations, Reward, fMRI, NAcc, Value, Motivation 
REWARDING EXPECTATION-CONFIRMATION

People dedicate a substantial portion of their time to interacting with other individuals. When we succeed in doing so, we feel better physically and psychologically (Baumeister and Leary, 1995; Tay et al., 2013; Cacioppo et al., 2014; Matthews and Tye, 2019). At the same time, other people also present one of the most complicated challenges we have to face. Understanding another person involves inferring hidden states based on fragmentary sensory, verbal and visceral cues, each of which conveys only a small amount of information. To simplify the highly demanding challenge of social cognition, perceivers use top-down predictions (e.g., stereotypes) that help make sense of others in a rapid fashion (Freeman and Johnson, 2016; Otten et al., 2017; Tamir and Thornton, 2018; Hutchinson and Barrett, 2019). Perceivers can thus seamlessly interact with their environment while refraining from the effortful construction of elaborative representations for each individual they encounter (Fiske and Neuberg, 1990; Macrae and Bodenhausen, 2000). For example, on her first day of school, a freshman might assume that her female peers may be interested in conversing about shopping. Utilizing these predictions, the freshman could effortlessly engage in spontaneous conversations with her new female peers, potentially facilitating her social bonds.

However, although they often facilitate interpersonal interaction, social predictions also impose a cost on perceivers. Individuals interpret ambiguous information in accordance with their expectations to confirm existing biases (Darley and Gross, 1983). Moreover, across multiple contexts individuals tend to adhere to predictions they have previously formed and fail to modify them even in the face of contradictory evidence (Hamilton and Sherman, 1996; Gregg et al., 2006; Roese and Sherman, 2007; Wyer, 2010; Dunsmoor et al., 2016). In the person perception domain, when perceivers first learn that someone is 'intelligent' and then subsequently learn that he is also 'envious', they form a favorably-skewed impression of that 
REWARDING EXPECTATION-CONFIRMATION

1 person; on the other hand, when perceivers learn about these same two character traits in reverse order, they form an unfavorable impression of the target (Asch, 1946; Sullivan, 2019). In the domain of stereotypes about social groups, perceivers typically do not update self-reported or implicitly measured preferences for a social group once formed (Gregg et al., 2006; Roese and Sherman, 2007). Together, such findings provide further evidence that people prefer to have their social predictions confirmed across multiple domains. To date, research has not been able to identify the sources that support the persistence of these initial predictions about other individuals. Here, we integrate insights from social psychology and neuroscience to explore the idea that perceivers prefer to 'stick' with their initial predictions because they attribute subjective value to the confirmation of these predictions. That is, we posit that targets who confirm our expectations about them (such as stereotype-consistent targets) will trigger a reward-like response similar to food, sex, or chocolate.

Several lines of research already hint at such an effect. Perceivers generally like individuals who conform to expectations more than individuals who violate them (Eagly and Karau, 2002; Phelan and Rudman, 2010; Stern et al., 2015); for example, observers typically prefer female teachers to male teachers, but like male leaders better than their equally competent female peers (Rudman et al., 2012; Moss-Racusin and Johnson, 2016). Similarly, participants express greater trust in targets that fit gender-based predictions (Olszanowski et al., 2018; Stern and Rule, 2018). Moreover, perceivers demonstrate similar effects for emotion-based expectations, regardless of the valence of the emotion (Chanes et al., 2018). Several theorists have suggested that perceivers may gradually develop a habitual hedonic response for targets conforming to normative expectations (Jost and Hunyady, 2003; Berridge, 2012; Huebner, 2016; Theriault et al., 2020). These suggestions dovetail with the well-documented aversive reactions people experience when 
REWARDING EXPECTATION-CONFIRMATION

1 confronted with violations of predictions and the uncertainty associated with such violations

2 (Festinger, 1957; Roese and Sherman, 2007; Gawronski, 2012; FeldmanHall and Shenhav, 2019;

3 Theriault et al., 2020). In a similar vein, when perceivers attempt to form an impression about an

4 expectation-violating social target, they effortfully process the information (Fiske and Neuberg,

5 1990) and show enhanced activity in several brain regions, including the dorsomedial prefrontal

6 cortex (Cloutier et al., 2011; Ames and Fiske, 2013; Mende-Siedlecki et al., 2013). Put together,

7 these positive and aversive responses motivate perceivers to seek expectation-consistent

8 information.

9 In spite of ample evidence for perceivers' motivation to confirm their social expectations,

10 scholars are still debating the mechanisms supporting the persistence of this motivation. Here we

11 suggest that neural activity can offer a novel insight on this topic. In recent years, scholars have

12 identified the involuntary effects of motivation and expectation in several neural systems, most

13 notably in the mesolimbic dopaminergic system (Kohli et al., 2018). Animal models suggest that

14 midbrain dopaminergic activity signals one's internal desire to obtain a goal (Berridge, 2012). In

15 humans, the motivation to experience positive effects manifests specifically in midbrain and striatal responses to better- or worse-than-expected information (Sharot et al., 2012; Lefebvre et

17 al., 2017; Charpentier et al., 2018). Likewise, participants expecting a painful stimulus

18 demonstrate increased striatal activity while experiencing pain, compared with participants who

19 do not expect to feel pain (Jepma et al., 2018; Schwarz et al., 2019; for a related effect of

20 negative stigma, see Welborn et al., 2020). Finally, a recent meta-analysis reported that when

21 perceivers agreed with expected group opinions, they demonstrated robust striatal activity, as

22 compared with times in which they deviated from the group consensus (Wu et al., 2016). These 
REWARDING EXPECTATION-CONFIRMATION

1 studies suggest that insofar as perceivers hold a motivation to experience a certain event, the

2 striatum responds to events that align with that motivation.

3 Notably, the involvement of the striatum hints at a potential mechanism driving the effects of

4 expectation and motivation. Researchers repeatedly identify striatal activity, and most

5 prominently activity in its ventral portion, in anticipation and receipt of various types of reward

6 (Schultz, 2000; Hare et al., 2008; Haber and Knutson, 2010). For example, the nucleus

7 accumbens (NAcc), located at the ventral-rostral tip of the striatum, responds both to primary

8 rewards (e.g., food or erotic) and secondary rewards (e.g., money or positive feedback) (Peters

9 and Büchel, 2010; Bartra et al., 2013; Sescousse et al., 2013). The NAcc also responds to social

10 experiences, such as engagement with attractive or smiling faces, prosocial actions, or placing

11 one's trust in peers (Harris and Fiske, 2010; Lin et al., 2012; Hackel et al., 2015; Krosch and

12 Amodio, 2019). As increased striatal responses are often associated with rewards, such a

13 response to events aligning with perceiver's motivation might indicate that these events are

14 rewarding as well.

Together, these studies suggest that consistency with stereotypes and other forms of interpersonal predictions is intrinsically rewarding. To test this hypothesis, we first measured

17 NAcc activity in response to information consistent or inconsistent with social expectations. target individuals on characteristics that either conformed to or violated interpersonal

21 region can serve as a marker of a neural reward response. If perceivers value having their social 
REWARDING EXPECTATION-CONFIRMATION

1 were associated with characteristics that confirm expectations compared to trials in which targets

2 violate them.

3 In addition, we assessed whether perceivers actively prefer expectancy-confirming social

4 information by creating experimental situations in which participants could trade money for the

5 chance to view targets with expectation-consistent characteristics. To do so, we relied on a

6 modified version of a "pay-per-view" task, previously used with human and non-human

7 primates, to measure the monetary value associated with expectancy-confirming and expectancy-

8 violating stimuli (Deaner et al., 2005; Tamir and Mitchell, 2012). If perceivers experience

9 expectancy-confirming information as intrinsically more valuable, we expected participants to

10 forgo money to rate individuals associated with expectancy-consistent rather than expectancy-

11 violating information.

12 Interestingly, social expectations can take multiple forms. For example, stereotypes relate

13 specific attributes to social groups regardless of personal knowledge about group members.

14 Conversely, we can construct detailed individuated expectations about familiar individuals, such

15 as personally familiar others or famous people (Fiske and Neuberg, 1990; Hamilton and

16 Sherman, 1996). Accordingly, we also probed whether predictions from these two distinct

17 sources evoked qualitatively different reward responses. Together, the results of four studies

18 support the hypothesis that perceivers are motivated to reaffirm their interpersonal forecasts, in

19 part because they experience the confirmation of social expectations as a powerful form of

20 subjective reward. 
REWARDING EXPECTATION-CONFIRMATION

In Study 1 we observed greater NAcc activity when participants saw targets associated with gender-stereotype-consistent information than when they saw targets associated with stereotypeviolating information. We scanned participants $(n=28$; here and in subsequent studies, the sample size reported includes only participants who did not fail pre-defined exclusion criteria; see Methods section) while they formed impressions about targets that varied in the degree to which they confirmed gender stereotypes. Gender stereotypes included various characteristics typically associated with men (e.g., "emotionally closed" or "CEO of a big company") or women (e.g., "loves children" or "an admired preschool teacher"). In each of 204 trials, participants first read a short description for 1.5 seconds and then saw the face of a target man or woman (see Fig S1A). Participants rated how likely the target was to have the presented characteristic (see SI results and Table S1 for behavioral results). We conducted three parallel analyses to examine whether the neural region most associated with reward—namely, the NAcc- — was more engaged when the target was associated with stereotype-derived expectations compared to when the target violated them. First, a whole-brain random-effects contrast identified regions that were more active for stereotype-consistent $>$ stereotype-violating trials $(p<0.05$, corrected; see Table S2 for full results). This analysis indicated a significantly greater response in the NAcc when the presented target matched the stereotypical expectation set by the preceding statement than when the target violated that expectation (Fig. 1A). Parallel results were obtained when we modeled expectation consistency as a continuous rather than dichotomized predictor (see Table S2 and SI Materials and Methods for full details).

Second, to confirm that this region overlapped with those responsive to rewards, we independently defined a neural regions of interest (ROI) based on spheres around peak voxels identified in a comprehensive meta-analysis (Bartra et al., 2013). In this independently defined 
1 region consistency with stereotypes resulted in significantly greater activity compared to their

2 violation [one-sided test: $t_{(54)}=3.53, p=0.0004$, Hedges's $g=0.37$ [95\% confidence intervals:

3 0.1-0.64], Fig. 1B]. Third, we corroborated this finding by defining ROIs from a task in which

4 participants received monetary rewards based on their performance [the Monetary Incentive

5 Delay (MID) task; see Materials and Methods] (Knutson et al., 2000). This analysis yielded

6 similar results $\left[t_{(54)}=2.87, p=0.0029, g=0.30[0.03-0.59]\right]$. Together, these patterns suggest

7 that seeing a person associated with a stereotypical characteristic triggers activation in the very

8 same region that responds to primary and secondary reinforcers, highlighting the intrinsic value

9 of stereotype confirmation. 


\section{REWARDING EXPECTATION-CONFIRMATION}

a

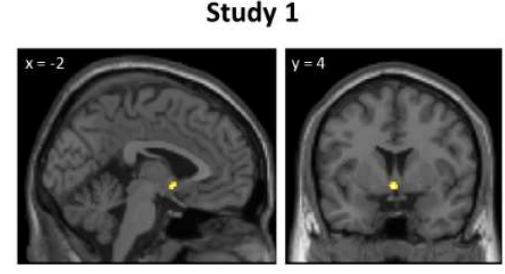

C
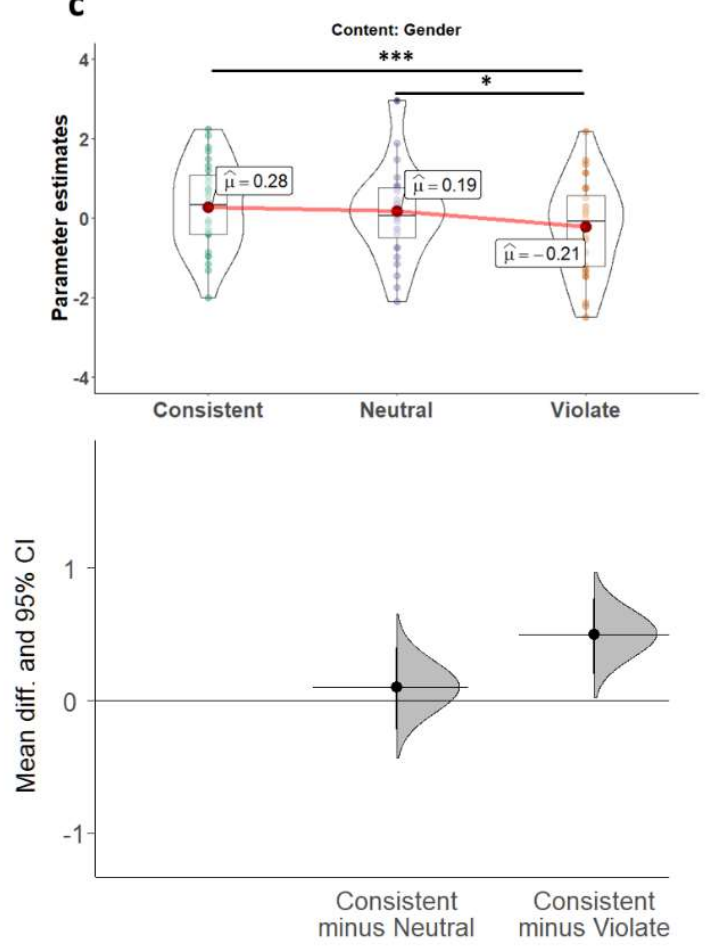

b
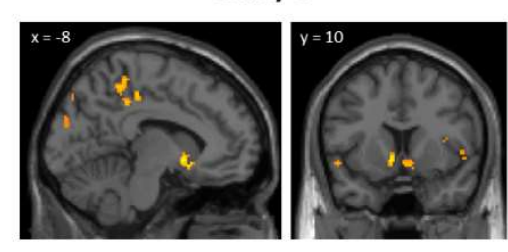

d
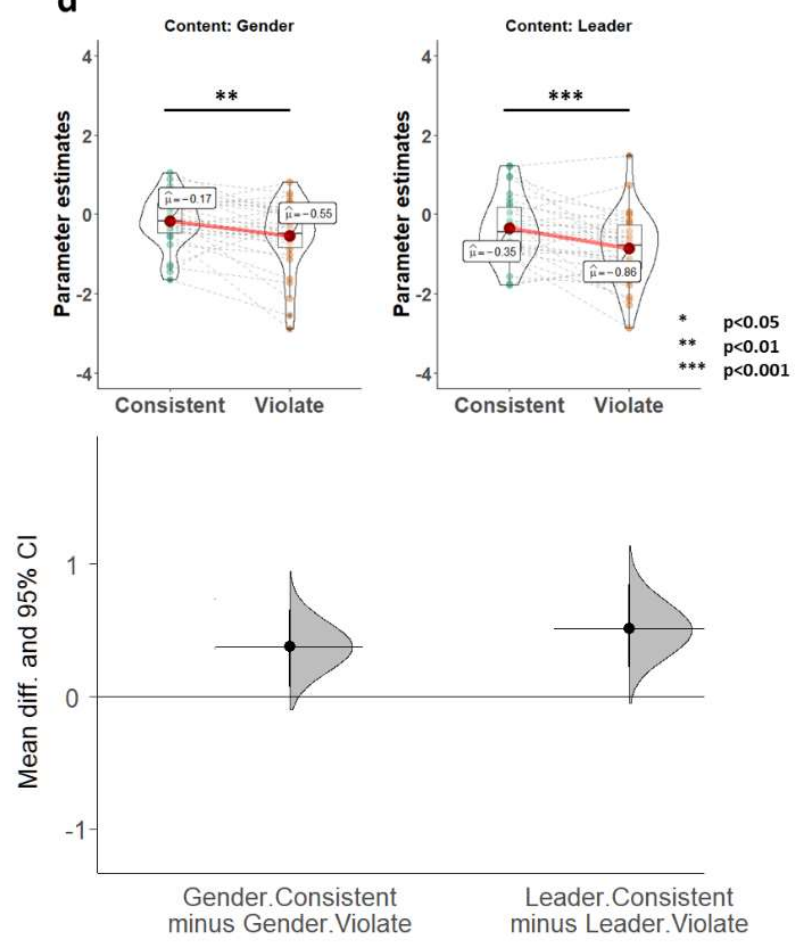

Figure 1. Neural responses associated with the confirmation of expectations about other individuals. (a) Whole-brain random-effects contrasts comparing expectation-consistent $>$ expectation-violating trials revealed activity in the nucleus accumbens (NAcc) in (A) Study 1 and (B) Study 3. (C) We independently defined a region of interest in the NAcc using a comprehensive meta-analysis (MNI coordinates: -6, 10, -6; 10, 12, -6). Analysis of parameter estimates in this region confirmed that the bilateral NAcc showed a stronger response during consistent than during violating trials in Study 1 and (D) Study 3. Upper panel: Across all figures, individual dots represent parameter estimates for individual participants. Each figure also visualizes the mean of each condition (as a red dot), the median (solid horizontal line), and first and third quartiles (boxplot). Lower panel: effect size (the mean difference between respective conditions, indicated by the black circles), the bootstrapped 95\% confidence intervals (illustrated by the vertical lines), and the resampled distribution of the effect size given the observed data, indicated by the curve (see Methods section).

Additionally, to investigate whether this NAcc activation is limited to stereotype-derived expectations, we included a third type of statements in our study: stereotype-neutral statements (e.g., "drinks coffee every morning"). Interestingly, we found that the overall NAcc response to 
REWARDING EXPECTATION-CONFIRMATION

targets associated with stereotype-neutral information was higher than the response to stereotype-violating information and not different from stereotype-consistent information [Fig. $1 \mathrm{C}$; Bonferroni corrected comparisons: neutral versus violating: Meta-analysis ROIs: $\mathrm{t}_{(54)}=2.83$, $\mathrm{p}=0.0195, \mathrm{~g}=0.29[0.09-0.51] ;$ MID ROIs: $\mathrm{t}_{(54)}=2.38, \mathrm{p}=0.062, \mathrm{~g}=0.25[0.04-0.47]$; neutral versus consistent: Meta-analysis ROIs: $\mathrm{t}_{(54)}=0.7, \mathrm{p}=0.76, \mathrm{~g}=0.07$ [-0.19-0.34]; MID ROIs: $\left.\mathrm{t}_{(54)}=0.49, \mathrm{p}=0.63, \mathrm{~g}=0.05[-0.18-0.28]\right]$. At first blush, this finding suggests that NAcc activation was modulated only by stereotype-inconsistent information, not that it was especially driven by stereotype-consistent information which, on average, did not differ from stereotypeneutral trials. However, additional analyses belie this interpretation. On each trial, participants rated the likelihood that the target could be described by the accompanying characteristic (e.g., “enjoys drinking coffee in the morning"). Importantly, the NAcc was activated during stereotype-neutral trials only when participants endorsed those characteristics as descriptive of the target and not when they rejected its applicability to a target (Meta-analysis ROIs: $\mathrm{F}_{(1,76.18)}=$ $15.67, \mathrm{p}=0.0002 ; \eta_{\mathrm{p}}{ }^{2}=0.17[0.06,0.29]$; MID ROIs: $\mathrm{F}_{(1,76.5)}=12.66, \mathrm{p}=0.0006 ; \eta_{\mathrm{p}}{ }^{2}=0.14$ $[0.04,0.26])$. In contrast, the preferential NAcc activation observed for stereotype-consistent trials was unaffected by participants' likelihood ratings (interaction between response and condition: Meta-analysis ROIs: $\mathrm{F}_{(1.77,47.68)}=5.4, \mathrm{p}=0.01, \eta_{\mathrm{p}}{ }^{2}=0.17[0.02,0.3]$; MID ROIs: $\mathrm{F}_{(1.87,50.4)}=4.01, \mathrm{p}=0.03, \eta_{\mathrm{p}}{ }^{2}=0.13[0.01,0.26]$; see Fig. 2. Stereotype-consistent trials: metaanalysis ROIs: $\mathrm{F}_{(1,76.18)}=0.2, \mathrm{p}>0.5 ; \eta_{\mathrm{p}}{ }^{2}=0.003[0,0.05]$; MID ROIs: $\mathrm{F}_{(1,76.5)}=0.63, \mathrm{p}>0.5$; $\left.\eta_{\mathrm{p}}{ }^{2}=0.005[0,0.06]\right)$. Together, these data points suggest that NAcc is activated specifically when one's expectations are confirmed, regardless of whether those expectations derive from culturally-salient stereotypes or from more personal and idiosyncratic sources. Finally, as for stereotype-neutral trials, stereotype-violating trials (e.g., a man who "enjoys shopping for 
bioRxiv preprint doi: https://doi.org/10.1101/2020.07.19.210757; this version posted April 28, 2021. The copyright holder for this preprint (which

was not certified by peer review) is the author/funder, who has granted bioRxiv a license to display the preprint in perpetuity. It is made available under aCC-BY-NC-ND 4.0 International license.

REWARDING EXPECTATION-CONFIRMATION

1 shoes") were associated with greater NAcc activation when participants endorsed the likelihood

2 of such characteristics (Meta-analysis ROIs: $\mathrm{F}_{(1,76.18)}=17.84, \mathrm{p}=0.0001 ; \eta_{\mathrm{p}}{ }^{2}=0.19[0.07,0.31]$;

3 MID ROIs: $\left.\mathrm{F}_{(1,76.5)}=15.76, \mathrm{p}=0.0002 ; \eta_{\mathrm{p}}^{2}=0.17[0.06,0.29]\right)$. 
a
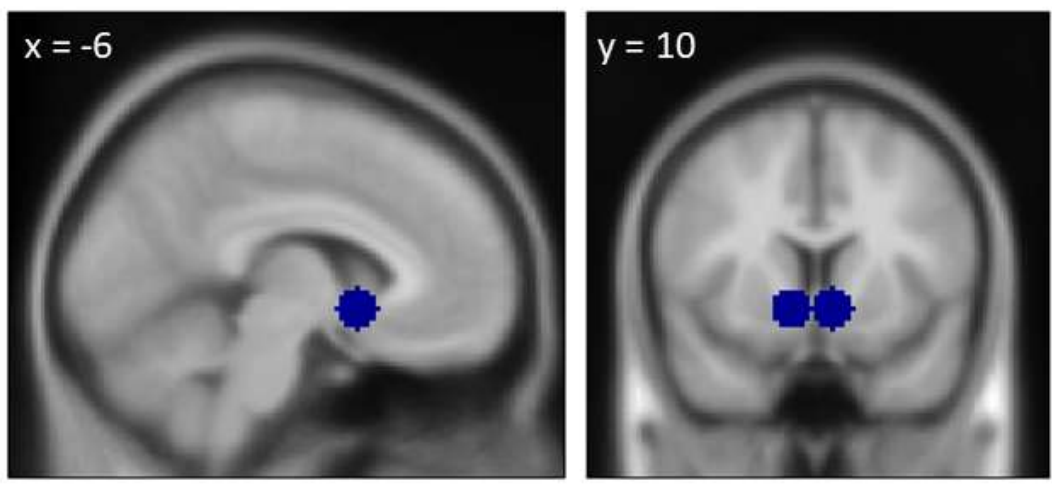

b
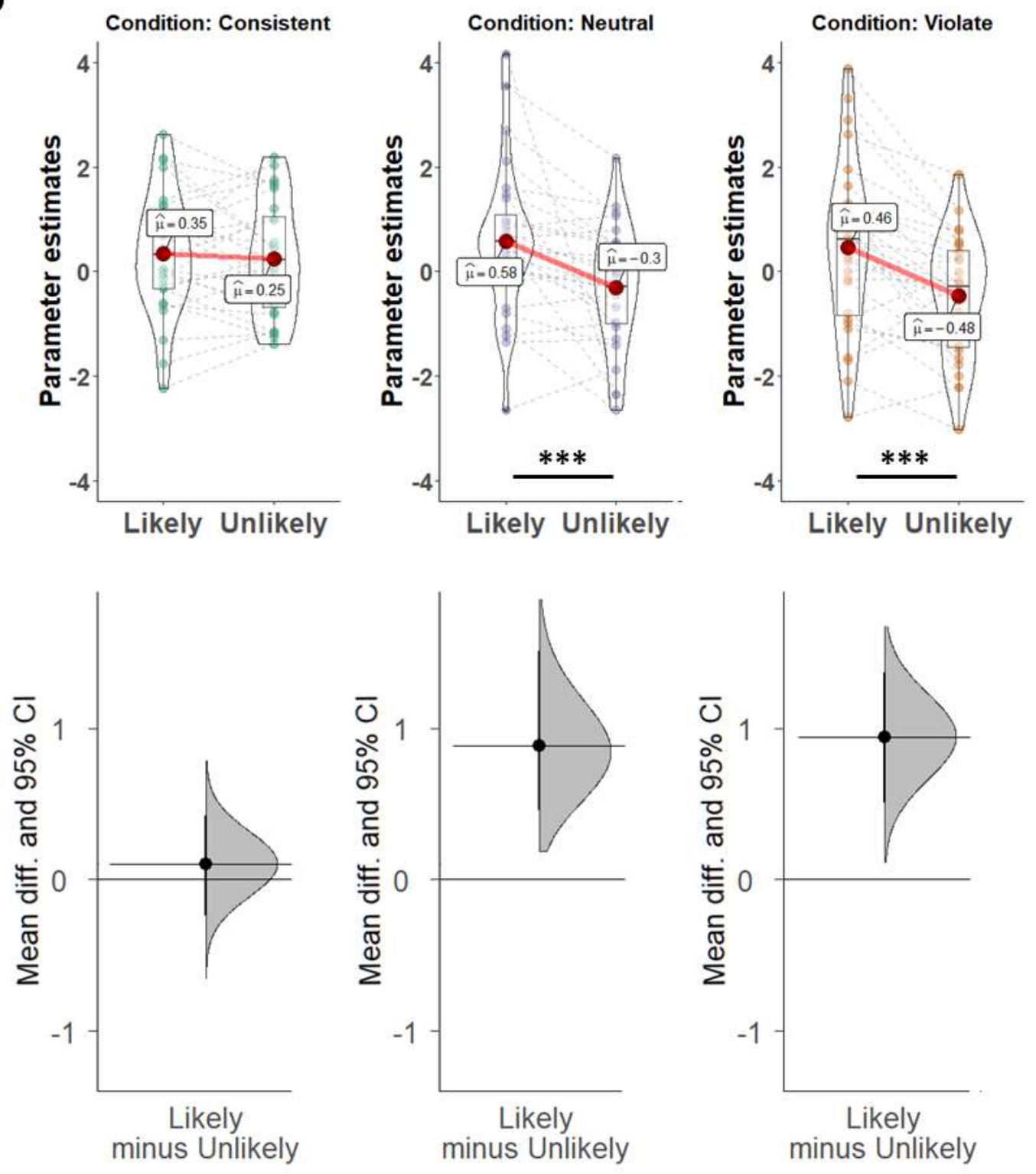
REWARDING EXPECTATION-CONFIRMATION

Figure 2. The effect of behavioral ratings of trials on neural responses. In each trial, participants indicated whether they thought the presented target was likely or unlikely to be associated with the presented statement. (A) The independently defined regions of interest in the NAcc. (B) We observed a significant interaction in the independently defined NAcc in Study 1: Participants' ratings modulated the neural response only for stereotype-neutral and stereotypeviolating targets, suggesting that stereotype-confirming targets are involuntarily rewarding.

\section{Study 2: The monetary value of stereotype confirmation}

Although activation of the NAcc often reflects the presence of rewarding stimuli (Bhanji and Delgado, 2014), this region can also respond to non-value related processes including information coding or salience effects (O’Doherty, 2014). To complement our initial neural results, in the preregistered Study 2 we examined a behavioral measure of the value associated with rating expectancy-confirming targets. Specifically, we tested how much money participants were willing to forgo to view stereotype-consistent instead of stereotype-violating targets.

Participants on Amazon Mechanical Turk ( $n \mathrm{~s}=174$ and 169 in Study 2a and 2b, respectively) made a series of choices to rate one of two target types: a stereotype-consistent target (e.g., a man who enjoys riding motorcycles) or a stereotype-violating target (e.g., a man who enjoys shopping for shoes), designated as "typical" and "atypical” respectively. After each choice, participants saw a target accompanied by a statement and rated the likelihood that the target would be associated with the statement on a 0-100 scale. Participants had up to 5 seconds for each phase of the task (see Fig S2). To avoid potentially different responses to male and female targets, Study 2a included only male faces and Study $2 \mathrm{~b}$ included only female faces. On each of the 25 trials, small monetary payoffs $(\$ 0.03-\$ 0.09$ in increments of 2 cents) were associated with each target choice. Participants received a subset of these payoffs as a monetary bonus for the task. Payoff amounts for each target choice varied across trials (and were occasionally equal), as did the location of the option for which participants received the larger amount. If consistency with stereotypes is intrinsically rewarding, participants should be willing to forgo money-to 
REWARDING EXPECTATION-CONFIRMATION

1 choose the lower-paying option - to see stereotype-consistent individuals. On the other hand, a

2 participant seeking to maximize monetary payoff should consistently choose the higher paying

3 option regardless of the stereotypicality of the information that follows.

$4 \quad$ We modeled the relative value of each target type by calculating the point of subjective

5 equivalence (PSE) between the two options. This value was derived by fitting a cumulative

6 normal distribution curve to participants' choices (Fig. 3A) and finding the monetary value at

7 which participants effectively chose arbitrarily between the two target types (Moscatelli et al.,

8 2012). Thus, the PSE represents the relative monetary value of one target type over another.

As predicted, participants demonstrated a significant preference for seeing stereotype-

consistent targets over stereotype-violating targets. When the two trial types shared the same and female targets, respectively (significantly more than chance, as indicated in a generalized mixed model analysis by an odds ratio of $1.4, Z=3.11, p=0.0019$ and an odds ratio of 1.41 , $Z=2.91, p=0.00369$ for the zero-centered intercept in Study $2 \mathrm{a}$ and 2b, respectively).

Moreover, the calculated PSE indicated that participants forewent an average of 0.34 and 0.335 cents per trial to rate a stereotype-consistent over a stereotype-violating target in Study 2a and

172 b, respectively (95\% Confidence Interval $[\mathrm{CI}]: 0.21-0.47, t_{(173)}=5.17, p<0.0001$, Cohen's $d=0.39[0.24-0.55]$ and CI: $0.25-0.43, t_{(168)}=7.3, p<0.0001, d=0.56[0.4-0.72]$ for the two

19 studies, respectively; Fig 3b). This PSE resulted in an average loss of $10 \%$ of potential earnings, as participants chose lower monetary amounts to view stereotype-consistent targets. Just as non-

21 human primates prefer to view dominant groupmates over receiving juice (Deaner et al., 2005)

22 and students are willing to forgo money to talk about themselves (Tamir and Mitchell, 2012) or 
REWARDING EXPECTATION-CONFIRMATION

1 to view attractive members of the opposite sex (Hayden et al., 2007), our participants gave up

2 money to view information that was in line with their stereotypical expectations.

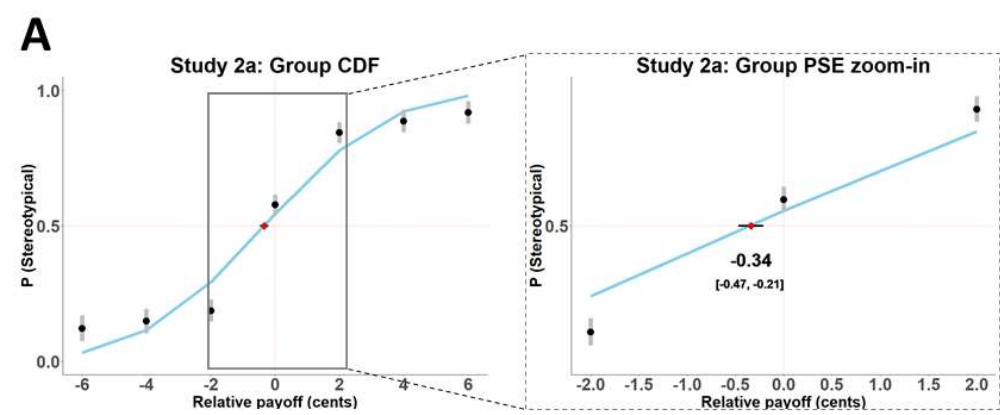

B
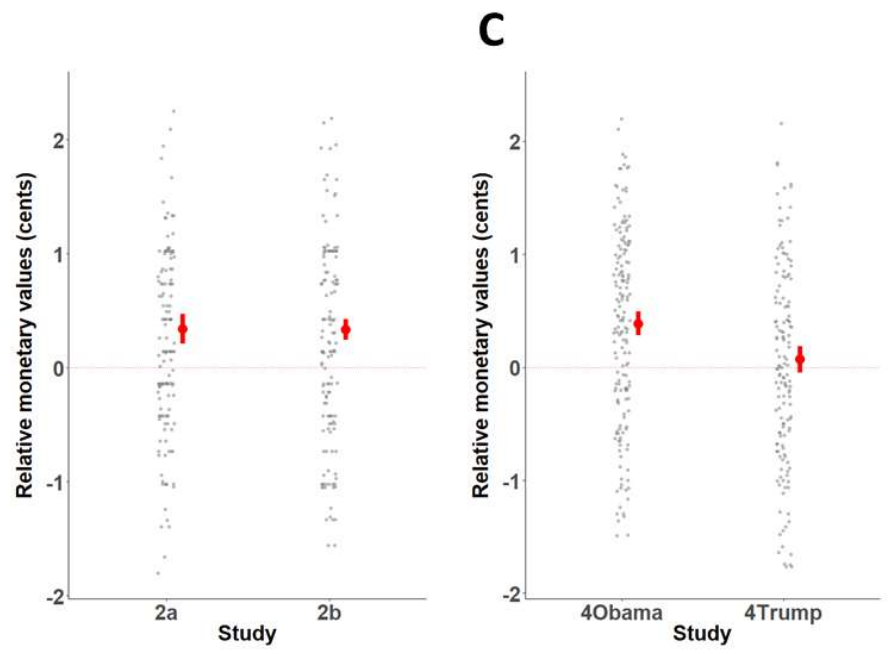

Figure 3. The monetary values of consistency with stereotype and person-specific expectations.

5 (A) Visualization of the cumulative distribution function we used to calculate the Point of

6 Subjective Equivalence (PSE), illustrated by group data from Study 2a. The x-axis represents the

7 difference between the monetary values associated with the two target types presented in each

8 trial. Each dot indicates the proportion of trials in which participants chose to rate a stereotype-

9 confirming over a stereotype-violating target. The PSE was calculated as the point at which a

10 cumulative normal distribution function, fit to these responses, passes 50\%. This point represents

11 the relative monetary value associated with one target type over the other. Negative values

12 indicate that participants preferred to incur a relative monetary loss to rate a confirming target.

13 Error bars depict 95\% confidence intervals. (B) Distribution of individual PSE values for Study

14 2. Rating stereotype-consistent targets in Studies $2 a$ and $2 b$ was associated with significantly

15 higher subjective value than rating stereotype-violating targets. Each gray dot depicts PSE for a

16 specific participant. Red dots indicate the sample mean. Error bars depict 95\% confidence

17 intervals. (C) Distribution of individual PSE values for Study 4. Rating Obama-consistent trials

18 was associated with significantly higher subjective value than rating Obama-violating trials. 
REWARDING EXPECTATION-CONFIRMATION

1

2 trials.

3

4

5

\section{Study 3: Neural response to interpersonal expectations}

Together, Studies 1 and 2 suggest that perceivers experience consistency with social expectations as intrinsically rewarding. However, we designed these studies primarily to test the effects of a specific type of social expectations - gender-based stereotypes. Although stereotypes are a significant source of interpersonal expectations, perceivers routinely make use of additional, idiosyncratic sources of information, especially for individuals with whom they are highly familiar. Does the reward value of expectancy-consistent information extend to personspecific predictions?

To examine this question, Study 3 assessed the responses of the neural reward system to the consistency with and violation of expectations regarding two highly familiar targets, the current and previous presidents of the United States at the time of the study: Donald Trump and Barack Obama, respectively. To facilitate comparison to Study 1, the preregistered Study 3 also included stereotype-derived expectations about unfamiliar targets. As in Study 1, participants $(n=30)$ rated how likely each of 240 specific statements described a specific man or woman or described Donald Trump or Barack Obama. We presented stereotype-related and person-specific statements in blocks of 15 trials per content domain for a total of 60 trials per condition (consistent/violating targets in the stereotype/person-specific domain). Person-specific statements included various characteristics typically associated with one - but not the otherleader (e.g., "Supports a wall along the borders" versus “Acts to support women's rights"). Participants first read a short statement for 1.5 seconds and then saw the face of a target (a man, 
REWARDING EXPECTATION-CONFIRMATION

1 a woman, Trump or Obama; see Fig S1C). Participants rated how likely the statement was to

2 describe the target (see Table S3 and SI Results for full details).

3 We conducted two parallel analyses to examine whether the NAcc was more engaged when

4 presented with information that was consistent expectations than with information that violated

5 them. First, a whole-brain random-effects contrast identified regions that were more active for

6 expectation-consistent $>$ expectation-violating trials $(\mathrm{p}<0.05$, corrected; see Table S3 for full

7 results). This analysis indicated significantly greater response in several regions, including the

8 NAcc, when the target was consistent with the expectation set by the preceding statement than

9 when the target violated that expectation (Fig. 1B).

In a second analysis we defined the NAcc via two independent procedures, first as bilateral spheres around peak voxels identified in a meta-analysis, and then by examining participants' However, we did not observe any difference between stereotypes and person-specific trials in any of the analyses. Specifically, a 2 X 2 repeated measures ANOVA over activity in bilateral NAcc revealed a main effect of expectation-consistency, with higher activation associated with

17 expectation-consistent compared to expectation-violation (meta-analysis ROIs: $F_{(1,29)}=21.89$, $p<0.0001, \eta^{2}{ }_{p}=0.43$ [0.19-0.58]; MID ROIs: $\left.F_{(1,29)}=11.2, p=0.002, \eta^{2}=0.28[0.07-0.46]\right)$.

19 Activation did not significantly differ between stereotype and person-specific content (metaanalysis ROIs: $F_{(1,29)}=3.64, p=0.07, \eta_{p}^{2}=0.11$ [0-0.29]; MID ROIs: $F_{(1,29)}=1.41, p=0.24$,

$\left.21 \eta_{p}^{2}=0.05[0-0.2]\right)$ and no interaction was observed between the factors (meta-analysis ROIs:

$F_{(1,29)}=0.31, p=0.58, \eta^{2}{ }_{p}=0.01[0-0.13]$; MID ROIs: $\left.F_{(1,29)}<0.01, p=0.99, \eta^{2}{ }_{p}<0.0001\right)$. 
1 domains when examined separately (meta-analysis ROIs: $F_{(1,54.8)}=5.96, p=0.0179$,

$2 \quad \eta_{p}^{2}=0.1[0.01-0.23]$ and $F_{(1,54.8)}=11.03, p=0.0016, \eta_{p}^{2}=0.17[0.04-0.31]$ for gender

3 stereotypes and person-specific expectations, respectively; MID ROIs: $F_{(1,55.47)}=4.36, p=0.04$,

$4 \quad \eta_{p}^{2}=0.07[0.001-0.2]$ and $F_{(1,55.47)}=4.45, p=0.04, \eta_{p}^{2}=0.07[0.002-0.2]$, respectively). Thus, consistency with social expectations triggered more activation in the NAcc than violation of such expectations, regardless of whether source of the expectation was general social knowledge (stereotypes) or person-specific knowledge. effects of subjective endorsement of characteristics for stereotype-based characteristics (but not by subjective endorsement of characteristics for stereotype-consistent targets (simple effects analyses: meta-analysis ROIs: $F_{(1,58)}=3.99, p=0.0503 ; \eta_{p}{ }^{2}=0.06[0,0.18]$; MID ROIs: $\eta_{p}{ }^{2}=0.003$ [0, 0.09]; MID ROIs: $\left.F_{(1,29)}=0.40, p>0.5, \eta_{p}^{2}=0.01[0,0.14]\right)$. In other words, unlike in Study 1, NAcc activation was insensitive to the degree to which a participant judges information to apply to a target, regardless of the stereotypicality of the target. Together, these results suggest that consistency with expectations about other targets is valuable for the two most

20 knowledge.

\section{Study 4: The monetary value of person-specific expectation-confirmation}

In Study 2, we observed that perceivers are willing to forgo money to view stereotype- 
REWARDING EXPECTATION-CONFIRMATION

1 effect extends to expectations about specific individuals, Study 4 replicated the procedure from

2 Study 2 using familiar individuals (Obama and Trump). On each of 32 trials, participants on

3 Prolific Academic ( $n=189$ and 172 in Study 4a and 4b, respectively) first chose between seeing

4 either an expectation-consistent or an expectation-violating target and then rated the target. Study

5 4a included only Obama as the target of statements and Study $4 \mathrm{~b}$ included only Trump. After

6 choosing the type of content they would like to see, participants rated the likelihood that a

7 specific statement would be associated with the target on a $0-100$ scale. Payoff amounts for each

8 choice varied across trials (and were occasionally equal), as did the option for which participants

9 received the larger amount. As in Study 2, we quantified the subjective monetary value of each

option by calculating the PSE between the two display types by fitting a cumulative normal

11 distribution curve to participants' choices and finding the monetary value at which participants

12 were indifferent to the two options. If participants experience consistency with expectation as

13 equally rewarding regardless of the target of expectations, then they should choose to forgo

14 money to rate statements consistent with Obama and Trump in Studies $4 \mathrm{a}$ and 4b, respectively.

The results from Study 4a indicate that participants preferred to see expectation-consistent

17 statements, participants chose the consistent statements $60 \%$ of the time (significantly more than

18 chance, as indicated in a generalized mixed model analysis by an odds ratio of $1.42, Z=4.74$,

21 expectancy-violating statement about Obama (95\% [CI]: $0.28-0.49, t_{(188)}=7.21, p<0.0001$,

$22 d=0.52[0.37-0.68]$; Fig 3C). However, the same was not true for Trump-related statements in

23 Study 4b. At equal payoff amounts, participants had no preference between 
1 expectancy-consistent and expectation-violating statements (choosing the consistent option 49\%

2 of the time; odds ratio of $1.01, z=0.13, p=0.9$ ), and the calculated PSE was not different from

3 zero (0.07 cents; [-0.05-0.19], $t_{(173)}=1.17, p=0.12, d=0.09[-0.06-0.24]$; Fig 3C). The

4 difference between the studies was significant $\left(t_{(328.29)}=2.28, p=0.023, d=0.25[0.03-0.46]\right)$.

5 However, this finding should be interpreted with caution, as our sample was demographically

6 skewed towards liberals, potentially diluting the effect of consistency with expectations from

7 Trump with additional factors (see Fig S4). Together, these findings suggest that the rewarding

8 effect of expectation-consistency is not limited to stereotypes, but also applies to knowledge

9 about specific individuals. Notably, however, not all sources of knowledge equally contribute to

10 the reward value; people were not willing to forgo monetary amounts to rate content consistent

11 with their expectations about Donald Trump (see SI results for potentially related findings in

12 Study 3).

\section{Discussion}

The human preference for consistent and predictable social interactions has long been acknowledged as a core motivational component driving everyday behavior (Festinger, 1957;

16 Gawronski, 2012). To predict the behavior of others, perceivers regularly employ biased

17 strategies to collect and interpret information that corresponds to their expectations (Lord et al.,

18 1979; Johnston and Macrae, 1994; Frimer et al., 2017; Falben et al., 2019; Oyserman and Yan,

19 2019). Here we provide evidence to suggest that humans associate expectation-consistent

20 information with intrinsic value, much like other forms of reward such as food or money. Our

21 findings suggest that this reward value is generated regardless of the source of the social

22 expectation. Participants were willing to forgo money to rate an expectation-consistent target

23 rather than its expectancy-violating counterpart. Moreover, doing so was associated with 
REWARDING EXPECTATION-CONFIRMATION

1 increased activity in a brain region in the neural reward circuitry, regardless of whether the target

2 was consistent with gender stereotypes or knowledge about US presidents. Put simply: people

3 find it rewarding to have their expectations (stereotypical or idiosyncratic) confirmed.

4 This line of research coincides with emerging theories that highlight the instrumental value of

5 behaviors and perceptions that fall in line with our expectations. In an early example of this

6 value, Allport (Allport, 1954) described a mental process in which 'A Scotsman who is

7 penurious delights us because he vindicates our prejudgment' (p.22). Some recent theories

8 suggest that, because most of our social expectations are anchored in our social environment,

9 repeated interaction with expectancy-confirming information leads to continuous reinforcement

10 of our expectations (Huebner, 2016; Oyserman and Yan, 2019; Peters, 2020). Once established,

11 these expectations induce motivations and cognitive representations that persist even in the face

12 of disconfirmation (Berridge, 2012; Uusberg et al., 2019; Yon et al., 2019). One theory further

13 suggests that the metabolic costs associated with the violation of expectations increase the

14 desirability of expectation-consistent behavior from an evolutionary standpoint (Theriault et al.,

15 2020). In line with these theories, the current studies demonstrate that information consistent

16 with social expectations is indeed associated with subjective value.

17 The current findings provide a neural extension to prominent accounts of implicit (i.e.,

18 involuntary) stereotyping and prejudice (Tibboel et al., 2015; Greenwald and Lai, 2020). Group-

19 based stereotypes typically draw on categorical distinctions to facilitate easier decision making

20 by enabling faster and more efficient processing of stereotype-confirming information (Roese

21 and Sherman, 2007). Stereotypes are also more familiar, thus allowing perceivers to process such

22 information fluently (e.g., Smith et al., 2006). Downstream, perceivers evaluate expectation-

23 confirming individuals more positively, allocate more economic resources to them, and judge 
REWARDING EXPECTATION-CONFIRMATION

1 them as more hirable (Phelan and Rudman, 2010; Stern et al., 2015; Stern and Rule, 2018).

2 Complementarily, violations of social expectations pose a threat to individuals and social

3 structures alike, which, in turn, often try to eliminate the threat and reinforce the original

4 expectation (Morgenroth and Ryan, 2020). Our results provide a candidate mechanism for these

5 effects, whereby the preference of expectation-consistent information translates into a subjective

6 value that shapes how we evaluate specific individuals (cf., Amodio and Devine, 2006).

7 Although our findings are mute with respect to the specific mechanism driving the rewarding

8 effect (e.g., a motivational goal to confirm expectations or processing fluency), our results hint at

9 when perceivers can assign value to expectation-violating information. In our task, behavior asymmetrically affected the neural response in the nucleus accumbens. Whereas stereotype-

11 consistent targets always evoked the same level of neural activity regardless of participants'

12 responses, in Study 1 stereotype-violating targets elicited enhanced NAcc activity only if

13 perceivers judged them as likely to be associated with the expectancy. This pattern suggests that

14 participants can assign value to stereotype-violating targets, perhaps depending on the

15 believability of the counter-stereotypical judgment.

The asymmetric effect of behavior on the neural response in the NAcc also suggests that our

17 findings do not result only from participants' desire to be correct in their predictions. Previous studies used objectively measurable performance to demonstrated increased ventral striatum activity when participants provided correct responses, either with external feedback (Ullsperger

20 and von Cramon, 2003; Tricomi and Fiez, 2008) or in its absence (Satterthwaite et al., 2012;

21 Ruissen et al., 2018). If the correspondence between the targets and predictions would have been

22 the sole process driving the effects, then behavioral ratings of targets would not have interacted

23 with types of prediction to modulate NAcc activity. Nonetheless, future studies should 
REWARDING EXPECTATION-CONFIRMATION

1 experimentally control for this alternative interpretation by, for example, including an explicit

2 prediction phase before presenting a target and yoking the identity of the target to participant's

3 prediction.

The expectation-consistency account of ventral striatum activity we put forward complements earlier hypotheses that activity in the mesolimbic circuit reflects prediction errors (Daw et al., 2011). Prediction errors refer to discrepancies between actual and expected outcomes, typically

7 in the context of learning (Niv and Schoenbaum, 2008). Numerous studies have found that the

8 ventral striatum increases its activity as the gap between the expected and the received outcome

9 grows (e.g., Glimcher, 2011; Ballard et al., 2018). However, the present results diverge from this

10 prediction error pattern. We observed increased striatal activity when an outcome- the target

11 face - was not different from the expected outcome; a prediction error account would suggest

12 that such activity should accompany unexpected information. Notably, unlike the vast majority

13 of studies exploring the prediction error account, the paradigms we used in the current

14 investigation did not involve learning. Participants saw each target only once during the entire

15 study and formed their expectations based solely on previously established knowledge.

16 Furthermore, our paradigm did not involve any explicit feedback. Therefore, participants had no

17 objective external verification of their predictions, nor did we directly measure their predictions.

18 Future studies could formally test whether striatal activity in response to expectancy-consistent

19 information also emerges when participants experience feedback and need to learn the new

20 information.

21 The current set of studies tested the value of expectancy-consistency through relatively

22 innocuous stereotypes and associations rather than overtly positive or negative bits of

23 information (with one potential exception of Trump-related statements for liberal participants; 
REWARDING EXPECTATION-CONFIRMATION

1 see below). Including only neutral or mildly-valenced statements allowed us to test the direct

2 effects of expectation-confirmation with little influence from potentially competing motivations,

3 such as social desirability. Therefore, we cannot determine whether perceivers will continue to

4 value stereotype-confirming information even when they are motivated to suppress them. Our

5 paradigms provided only indirect evidence on this question. In Study 3, our sample consisted of

6 liberal participants (average rating of 3.37 on a 1-9 scale, ' 1 ' denoting extremely liberal and '9'

7 denoting extremely conservative) for whom information consistent with Donald Trump might be

8 aversive. However, these participants demonstrated comparable activation in the neural reward

9 circuitry in response to statements about Donald Trump and Barack Obama, implying that seeing expectation-confirming information is rewarding regardless of the valence of these statements. In

11 Study 4, conversely, participants (mean difference of 64 points on a 0-100 scale in favor of liking

12 Barack Obama; see SI Results) did not choose to incur a cost to see Trump-consisting

13 information, suggesting that additional motivations affected their behavior. These first steps

14 warrant further research to characterize the precise mechanisms contributing to subjective value

15 perceivers attribute to confirmation of expectation and the subsequent behaviors associated with

16 this value.

An additional and important future route of investigation should explore the generalizability

18 of ou $r$ findings to non-social contexts. Here we focused on expectations concerning social

19 targets - unfamiliar men and women as well as familiar targets. We cannot ascertain whether

20 similar effects would emerge for non-social expectations, such as about inanimate objects or the

21 weather. Given some accounts suggesting that social information processing has a preferred

22 status in the primate brain (Adolphs, 2009; Atzil et al., 2018; Lockwood et al., 2020), we might

23 expect that (a) the subjective value attributed to consistency should be greater for the kinds of 
REWARDING EXPECTATION-CONFIRMATION

1 social expectations studied here and (b) confirmation of social expectations would lead to

2 responses similar to reward-like responses for primary reinforcers like food.

3 Altogether, these findings join a growing body of literature that characterizes how our prior

4 beliefs modulate information-processing to fortify a world view and protect established

5 expectations (Golman et al., 2017; Charpentier et al., 2018; Jepma et al., 2018; Gershman, 2019;

6 Yon et al., 2019). We suggest that the subjective value imbued upon targets who conform to

7 societal expectations may serve to sustain multiple stereotype- and expectation-induced biases.

8 To mitigate the negative implications associated with these expectations, society will need to

9 acknowledge the subjective value associated with their confirmation.

\section{Materials and Method}

\section{Study Design.}

Materials. To create expectation-setting statements we generated a list of verbal statements

14 included 136 gender-related and 68 gender-neutral statements (see SI Materials and Methods).

15 We verified the stereotypicality of these statements in a pilot study $(n=78)$ in which participants

16 from the local community indicated how typical the characteristic was for a specific gender on a

17 visual scale of 0 ("very untypical") to 100 ("very typical"; the scale had no other tick marks).

18 Each participant was randomly assigned to rate each statement either for men or for women.

19 Participants were instructed to base their ratings on how they thought the average person would

20 respond. This verification procedure was successful; men were associated with men-stereotypic

21 statements more than women (mean difference: 25.7$)$ and women were associated with women-

22 stereotypic statements more than men (mean difference: 25.1 ). Overall, the statements contained 
REWARDING EXPECTATION-CONFIRMATION

2-9 words (mean: 4.69, S.D: 1.44; no difference between experimental conditions, $p>0.2$ ) and 9-45 characters (mean: 26.68, S.D.: 7.69; $p>0.18$ ). Studies 3 and 4 further included 120 personspecific statements pertaining to Barack Obama and Donald Trump. A total of 243 participants from Amazon Mechanical Turk rated a sample of 60 of these statements, randomly determined per participant. On each trial participants indicated how typical the presented characteristic was for the two targets (a separate scale for each target; the two scales were presented simultaneously with a randomly determined order). Obama was associated with Obama-related statements more than Trump (mean difference: 56.1) and Trump was associated with Trump-related statements more than Obama (mean difference: 54.5). Overall, the statements contained 2-9 words (mean: 4.65, S.D: 1.52; no difference between experimental conditions, $p>0.5$ ) and 11-45 characters (mean: 28.33, S.D.: 8.43; $p>0.5$ ).

Studies 1 and 3. Twenty-eight individuals participated in Study 1 and 30 individuals participated in Study 3. Additional participants were excluded due to excessive motion, technical issues or lack of response to more than $20 \%$ of trials ( 3 and 6 participants from Studies 1 and 3 , respectively). All participants provided informed consent in a manner approved by the Committee on the Use of Human Subjects in Research at Harvard University. Study 3 was preregistered (https://osf.io/h9c6x/?view_only=6fa03fc0ceb04e2083db9e485dbe6615). See SI for demographic information. The current sample size allowed a power of 0.8 to detect a medium effect size (Cohen's $d=0.5$ ) in the planned one-tailed contrast between expectation-consistent and expectation-violating targets at the region of interest. In both studies participants formed impressions about target individuals. On each trial, participants first saw a statement for 1.5 seconds. The statements in Study 1 described a stereotypically neutral, stereotypically male, or stereotypically female characteristic; statements in Study 3 described a characteristic which was 
REWARDING EXPECTATION-CONFIRMATION

1 either stereotypically male or female or closely associated with Barack Obama or Donald Trump

2 (see https://osf.io/tgja3/?view_only=d849bad1b606474f80c1a3e40e740875 for open materials).

3 Next, participants saw the statement with a face of a man or a woman (in Study 1; Study 3 also

$4 \quad$ included face images of the relevant leaders). The statement-face pair appeared on screen for 4

5 additional seconds ( 3.5 seconds in Study 3 ) for a total of 5.5 seconds ( 5 seconds) per trial. Each

6 trial ended with a 0.5 second fixation crosshair. Participants used their left hand to indicate how

7 likely the presented target was to be described by the specific characteristic using a 4-point scale

8 (1- 'very unlikely'; 4 -'very likely'). Participants responded while the pair appeared on screen.

9 Trials in both studies were separated by variable intertrial intervals of 0-9s (Dale, 1999) optimized for our contrast of interest (see SI Materials and Methods for details).

Studies 2 and 4. A total of 343 participants were included in Study 2 (174 in Study 2a) and 361 in Study 4 (189 in Study 4a). Additional participants were excluded by criteria set in the preregistered protocols for each study (see SI Materials and Methods for details; see also

17 sufficient power (0.8) to detect a small effect size (Cohen's $d=0.2)$ in a one-sample t-test for each study. Informed consent was obtained from all participants in a manner approved by the Committee on the Use of Human Subjects at Harvard University.

\section{Statistical Analysis}

Studies 1 and 3. To localize brain regions associated with the processing of rewarding

22 stimuli, we defined 8-mm spheres around peak coordinates drawn from a comprehensive metaanalysis (Bartra et al., 2013). To functionally identify these brain regions, participants in both 
REWARDING EXPECTATION-CONFIRMATION

1 studies completed a Monetary Incentive Delay (MID) task (Knutson et al., 2000) immediately

2 after the impression formation task (see Fig. S1B and SI Materials and Methods for details). This

3 task allows the identification of monetary-reward-sensitive ROIs by comparing trials in which

4 participants won money to trials in which participants could not earn any reward. We extracted

5 and averaged parameter estimates across voxels in each ROI per condition of interest and

6 analyzed them using within-participant ANOVAs as implemented by afex package (Singmann et

7 al., 2018) for R, version 0.22-1. We plotted the results using the package ggstatsplot (Patil,

8 2018), version 0.2.0. Additionally, we plotted the mean effect size and the bootstrapped 95\%

9 confidence intervals using the package dabestr (Ho et al., 2019), version 0.2.2.

We collected neuroimaging data with a 3T Siemens Prisma scanner system (Siemens Medical

11 Systems, Erlangen, Germany). First, we acquired high-resolution anatomical images using a T1-

12 weighted 3D MPRAGE sequence. Next, whole brain functional images were collected using a

13 simultaneous multi-slice (multiband) T2*-weighted gradient echo sequence (TR $=2000 \mathrm{msec}$,

$14 \mathrm{TE}=30 \mathrm{msec}$, voxel size $=2 \times 2 \times 2 \mathrm{~mm} 3,75$ slices auto-aligned to -25 degrees of the AC-PC

15 line). Participants completed four impression formation task runs consisting of 229 volumes each

16 (245 volumes in Study 3). Finally, participants completed the MID task in a single run consisting

17 of 110 volumes using identical parameters to those mentioned above. We used SPM12 version

186225 (Wellcome Department of Cognitive Neurology, London, UK) to process and analyze the

19 fMRI data. Data were corrected for differences in acquisition time between slices, corrected for

20 inhomogeneities in the magnetic field using fieldmap (Cusack and Papadakis, 2002), realigned to

21 the first image to correct for head movement, unwarped to account for residual movement-

22 related variance and co-registered with each participant's anatomical data. Functional data were

23 then transformed into a standard anatomical space ( $2 \mathrm{~mm}$ isotropic voxels) based on the 
REWARDING EXPECTATION-CONFIRMATION

1 ICBM152 brain template (Montreal Neurological Institute). Normalized data were then spatially

2 smoothed (6 mm full-width at half-maximum, FWHM) using a Gaussian Kernel (see SI

3 Materials and Methods for full details of scanning and analysis procedures). We analyzed

4 preprocessed data using a general linear model in which we modeled trials as boxcar functions

5 with an onset at face presentation (1.5s after statement presentation) and with variable duration

6 determined per trial by reaction time to control for effects of reaction time on the neural response

7 (Grinband et al., 2008). Our main analysis included a model in which we conditionalized trials

8 based on trial type (stereotype-consistent, stereotype-neutral or stereotype-violating trials in

9 Study 1; stereotype-consistent, stereotype-violating, person-specific-confirming and personspecific-violating trials in Study 3). In our secondary analysis (Fig 2) we split each of the trial

11 types included in the main analysis with two regressors, one in which participants provided a

12 "Likely" rating and one in which they provided an "Unlikely" rating. We convolved events with 13 a canonical hemodynamic response function and its temporal derivative and included additional 14 covariates of no interest (session mean, no response trials, six motion parameters and their 15 temporal derivative). The final first-level GLM was high-pass filtered at $128 \mathrm{~s}$. Analyses were 16 performed individually for each participant, and contrast images were subsequently entered into

17 a second-level analysis treating participants as a random effect. We report activations that

18 survived a threshold of $\mathrm{p}<0.001$ (uncorrected) at the voxel level and (cluster-size) corrected to

$19 \mathrm{p}<0.05$ at the cluster level using Monte Carlo simulations (1,000 iterations) with the current

20 imaging and analysis parameters (Slotnick, 2017).

21 Studies 2 and 4. We analyzed choice data with logit generalized linear mixed models as

22 implemented in the lme4 package version 1.1-14 (Bates et al., 2014) for R version 3.4.2 (R Core

23 Team, 2017). We used the probit link and included fixed effects for the intercept and for the 
REWARDING EXPECTATION-CONFIRMATION

1 value difference between the two target types, as well as random effects for the intercepts for

2 participants for the by-participant random slopes for the fixed effect of value difference. We

3 calculated the PSE (and the related SEs) for the difference between the two target types for each

$4 \quad$ study by the Delta Method as implemented in the MixedPsy package (Moscatelli et al., 2012;

5 Moscatelli and Balestrucci, 2017) for R. The Delta Method relies on responses to all trials

6 aggregated across participants in a generalized linear model to approximate the PSE with a

7 Gaussian distribution (Moscatelli et al., 2012) and to plot the cumulative distribution function.

8 The model included the difference between the two target types on each trial as the predictor

9 value and a binary outcome (stereotypical/knowledge-consistent option chosen) as the predicted

10 value, with the probit link. To present individual-level data (Figure 3B and 3C), we calculated

11 the PSE for each participant. This resulted in some PSE values that exceeded the possible values

12 in the current studies, as PSE models do not accurately reflect behavior when one choice option

13 is rarely selected, as was the case for some participants. Therefore, we excluded participants for

14 whom the calculated PSE value exceeded \pm 6 ( $n=4-14$ across studies). 
REWARDING EXPECTATION-CONFIRMATION

\section{References}

Adolphs, R. (2009). The social brain: Neural basis of social knowledge. Annual Review of Psychology, 60, 693-716

Allport, G.W. (1954). The nature of prejudice. Oxford, England: Addison-Wesley.

Ames, D.L., Fiske, S.T. (2013). Outcome dependency alters the neural substrates of impression formation. NeuroImage, 83, 599-608

Amodio, D.M., Devine, P.G. (2006). Stereotyping and evaluation in implicit race bias: Evidence for independent constructs and unique effects on behavior. Journal of Personality and Social Psychology, 91, 652-61

Asch, S.E. (1946). Forming impressions of personality. Journal of Abnormal and Social Psychology, 41, 258-90

Atzil, S., Gao, W., Fradkin, I., et al. (2018). Growing a social brain. Nature Human Behaviour, 2

Ballard, I., Miller, E.M., Piantadosi, S.T., et al. (2018). Beyond Reward Prediction Errors: Human Striatum Updates Rule Values during Learning. Cerebral Cortex, 28, 3965-75

Bartra, O., McGuire, J.T., Kable, J.W. (2013). The valuation system: A coordinate-based metaanalysis of BOLD fMRI experiments examining neural correlates of subjective value. NeuroImage, 76, 412-27

Bates, D.M., Maechler, M., Bolker, B., et al. (2014). lme4: Linear mixed-effects models using Eigen and S4

Baumeister, R.F., Leary, M.R. (1995). The need to belong: Desire for interpersonal attachments as a fundamental human motivation. Psychological Bulletin, 117, 497-529

Berridge, K.C. (2012). From prediction error to incentive salience: Mesolimbic computation of reward motivation. European Journal of Neuroscience, 35, 1124-43

Bhanji, J.P., Delgado, M.R. (2014). The social brain and reward: Social information processing in the human striatum. Wiley Interdisciplinary Reviews: Cognitive Science, 5, 61-73

Cacioppo, J.T., Cacioppo, S., Boomsma, D.I. (2014). Evolutionary mechanisms for loneliness. Cognition and Emotion, 28, 1-22

Chanes, L., Wormwood, J.B., Betz, N., et al. (2018). Facial expression predictions as drivers of social perception. Journal of Personality and Social Psychology, 114, 380-96

Charpentier, C.J., Bromberg-Martin, E.S., Sharot, T. (2018). Valuation of knowledge and ignorance in mesolimbic reward circuitry. Proceedings of the National Academy of Sciences, 115, E7255-64

Cloutier, J., Gabrieli, J.D.E., O’Young, D., et al. (2011). An fMRI study of violations of social expectations: When people are not who we expect them to be. NeuroImage, 57, 583-88

Cusack, R., Papadakis, N. (2002). New robust 3-D phase unwrapping algorithms: Application to magnetic field mapping and undistorting echoplanar images. NeuroImage, 16, 754-64 
REWARDING EXPECTATION-CONFIRMATION

Dale, A.M. (1999). Optimal experimental design for event-related fMRI. Human Brain Mapping, 8, 109-14

Darley, J.M., Gross, P.H. (1983). A hypothesis-confirming bias in labeling effects. Journal of Personality and Social Psychology, 44, 20-33

Daw, N.D., Gershman, S.J., Seymour, B., et al. (2011). Model-based influences on humans' choices and striatal prediction errors. Neuron, 69, 1204-15

Deaner, R.O., Khera, A. V., Platt, M.L. (2005). Monkeys pay per view: Adaptive valuation of social images by rhesus macaques. Current Biology, 15, 543-48

Dunsmoor, J.E., Kubota, J.T., Li, J., et al. (2016). Racial stereotypes impair flexibility of emotional learning. Social Cognitive and Affective Neuroscience, 11, 1363-73

Eagly, A.H., Karau, S.J. (2002). Role congruity theory of prejudice toward female leaders. Psychological Review, 109, 573-98

Falben, J., Tsamadi, D., Golubickis, M., et al. (2019). Predictably confirmatory: The influence of stereotypes during decisional processing. Quarterly Journal of Experimental Psychology, 72, 2437-51

FeldmanHall, O., Shenhav, A. (2019). Resolving uncertainty in a social world. Nature Human Behaviour, 3, 426-35

Festinger, L. (1957). A theory of cognitive dissonance (Vol. 2). Stanford university press.

Fiske, S.T., Neuberg, S.L. (1990). A continuum of impression formation, from category-based to individuating processes: Influences of information and motivation on attention and interpretation. In: M. P. Zanna (ed). Advances in Experimental Social Psychology. Academic Press, p. 1-74.

Freeman, J.B., Johnson, K.L. (2016). More than meets the eye: Split-second social perception. Trends in Cognitive Sciences, 20, 362-74

Frimer, J.A., Skitka, L.J., Motyl, M. (2017). Liberals and conservatives are similarly motivated to avoid exposure to one another's opinions. Journal of Experimental Social Psychology, 72, $1-12$

Gawronski, B. (2012). Back to the future of dissonance theory: Cognitive consistency as a core motive. Social Cognition, 30, 652-68

Gershman, S.J. (2019). How to never be wrong. Psychonomic Bulletin and Review, 26, 13-28

Glimcher, P.W. (2011). Understanding dopamine and reinforcement learning: The dopamine reward prediction error hypothesis. Proceedings of the National Academy of Sciences of the United States of America, 108, 15647-15654

Golman, R., Hagmann, D., Loewenstein, G. (2017). Information avoidance. Journal of Economic Literature, 55, 96-135

Greenwald, A.G., Lai, C.K. (2020). Implicit social cognition. Annual Review of Psychology, 71 Gregg, A.P., Seibt, B., Banaji, M.R. (2006). Easier done than undone: Asymmetry in the 
REWARDING EXPECTATION-CONFIRMATION

malleability of implicit ireferences. Journal of Personality and Social Psychology, 90, 1-20

Grinband, J., Wager, T.D., Lindquist, M., et al. (2008). Detection of time-varying signals in event-related fMRI designs. NeuroImage, 43, 509-20

Haber, S.N., Knutson, B. (2010). The reward circuit: Linking primate anatomy and human imaging. Neuropsychopharmacology, 35, 4-26

Hackel, L.M., Doll, B.B., Amodio, D.M. (2015). Instrumental learning of traits versus rewards: dissociable neural correlates and effects on choice. Nature Neuroscience, 18, 1233-40

Hamilton, D.L., Sherman, S.J. (1996). Perceiving persons and groups. Psychological Review, 103, 336-55

Hare, T.A., O'Doherty, J.P., Camerer, C.F., et al. (2008). Dissociating the role of the orbitofrontal cortex and the striatum in the computation of goal values and prediction errors. Journal of Neuroscience, 28, 5623-30

Harris, L.T., Fiske, S.T. (2010). Neural regions that underlie reinforcement learning are also active for social expectancy violations. Social Neuroscience, 5, 76-91

Hayden, B.Y., Parikh, P.C., Deaner, R.O., et al. (2007). Economic principles motivating social attention in humans. Proceedings of the Royal Society B, 274, 1751-56

Ho, J., Tumkaya, T., Aryal, S., et al. (2019). Moving beyond P values: data analysis with estimation graphics. Nature Methods, 16, 565-66

Huebner, B. (2016). Implicit bias, reinforcement learning, and scaffolded moral cognition. In: M. Brownstein, J. Saul (eds). Implicit Bias and Philosophy, Volume 1: Metaphysics and Epistemology. New York, NY: Oxford University Press, p. 47-79.

Hutchinson, J.B., Barrett, L.F. (2019). The power of predictions: An emerging paradigm for psychological research. Current Directions in Psychological Science, 28, 280-91

Jepma, M., Koban, L., Doorn, J., et al. (2018). Behavioural and neural evidence for selfreinforcing expectancy effects on pain. Nature Human Behaviour, 2, 838-55

Johnston, L.C., Macrae, C.N. (1994). Changing social stereotypes: The case of the information seeker. European Journal of Social Psychology, 24, 581-92

Jost, J., Hunyady, O. (2003). The psychology of system justification and the palliative function of ideology. European Review of Social Psychology, 13, 111-53

Knutson, B., Westdorp, A., Kaiser, E., et al. (2000). FMRI visualization of brain activity during a monetary incentive delay task. NeuroImage, 12, 20-27

Kohli, A., Blitzer, D.N., Lefco, R.W., et al. (2018). Using Expectancy Theory to quantitatively dissociate the neural representation of motivation from its influential factors in the human brain: An fMRI study. NeuroImage, 178, 552-61

Krosch, A.R., Amodio, D.M. (2019). Scarcity disrupts the neural encoding of Black faces: A aocioperceptual pathway to discrimination. Journal of Personality and Social Psychology, $117,859-75$ 
REWARDING EXPECTATION-CONFIRMATION

Lefebvre, G., Lebreton, M., Meyniel, F., et al. (2017). Behavioural and neural characterization of optimistic reinforcement learning. Nature Human Behaviour, 1, 1-9

Lin, A., Adolphs, R., Rangel, A. (2012). Social and monetary reward learning engage overlapping neural substrates. Social Cognitive and Affective Neuroscience, 7, 274-81

Lockwood, P.L., Apps, M.A.J., Chang, S.W.C. (2020). Is there a 'social' brain? Implementations and algorithms. Trends in Cognitive Sciences, 24, 802-13

Lord, C.G., Ross, L., Lepper, M.R. (1979). Biased assimilation and attitude polarization: The effects of prior theories on subsequently considered evidence. Journal of Personality and Social Psychology, 37, 2098-2109

Macrae, C.N., Bodenhausen, G. V. (2000). Social cognition: Thinking categorically about others. Annual review of psychology, 51, 93-120

Matthews, G.A., Tye, K.M. (2019). Neural mechanisms of social homeostasis. Annals of the New York Academy of Sciences, 1-21

Mende-Siedlecki, P., Cai, Y., Todorov, A. (2013). The neural dynamics of updating person impressions. Social Cognitive and Affective Neuroscience, 8, 623-31

Morgenroth, T., Ryan, M.K. (2020). The Effects of Gender Trouble: An Integrative Theoretical Framework of the Perpetuation and Disruption of the Gender/Sex Binary. Perspectives on Psychological Science

Moscatelli, A., Balestrucci, P. (2017). Psychophysics with R: The R package MixedPsy

Moscatelli, A., Mezzetti, M., Lacquaniti, F. (2012). Modeling psychophysical data at the population-level: The generalized linear mixed model. Journal of Vision, 12, 26-26

Moss-Racusin, C.A., Johnson, E.R. (2016). Backlash against male elementary educators. Journal of Applied Social Psychology, 46, 379-93

Niv, Y., Schoenbaum, G. (2008). Dialogues on prediction errors. Trends in Cognitive Sciences, $12,265-72$

O’Doherty, J.P. (2014). The problem with value. Neuroscience and Biobehavioral Reviews, 43, 259-68

Olszanowski, M., Kaminska, O.K., Winkielman, P. (2018). Mixed matters: fluency impacts trust ratings when faces range on valence but not on motivational implications. Cognition \& Emotion, 32, 1032-51

Otten, M., Seth, A.K., Pinto, Y. (2017). A social Bayesian brain: How social knowledge can shape visual perception. Brain and Cognition, 112, 69-77

Oyserman, D., Yan, V.X. (2019). Making meaning: A culture-as-situated-cognition approach to the consequences of cultural fluency and disfluency. In: D. Cohen, S. Kitayama (eds). Handbook of Cultural Psychology. New York, NY: Guilford Press, p. 536-65.

Patil, I. (2018). ggstatsplot: 'ggplot2' Based Plots with Statistical Details

Peters, J., Büchel, C. (2010). Neural representations of subjective reward value. Behavioral Bran 
REWARDING EXPECTATION-CONFIRMATION

Research, 213, 135-41

Peters, U. (2020). What is the function of confirmation bias? Erkenntnis

Phelan, J.E., Rudman, L.A. (2010). Reactions to ethnic deviance: The role of backlash in racial stereotype maintenance. Journal of Personality and Social Psychology, 99, 265-81

Roese, N.J., Sherman, J.W. (2007). Expectancy. In: E. T. Higgins, A. W. Kruglanski (eds). Social Psychology: handbook of basic principles. The Guilford Press, p. 91-115.

Rudman, L.A., Moss-Racusin, C.A., Phelan, J.E., et al. (2012). Status incongruity and backlash effects: Defending the gender hierarchy motivates prejudice against female leaders. Journal of Experimental Social Psychology, 48, 165-79

Ruissen, M.I., Overgaauw, S., De Bruijn, E.R.A. (2018). Being right, but losing money: The role of striatum in joint decision making. Scientific Reports, 8, 1-11

Satterthwaite, T.D., Ruparel, K., Loughead, J., et al. (2012). Being right is its own reward: Load and performance related ventral striatum activation to correct responses during a working memory task in youth. NeuroImage, 61, 723-29

Schultz, W. (2000). Multiple reward signals in the brain. Nature Reviews Neuroscience, 1, 199207

Schwarz, K.A., Sprenger, C., Hidalgo, P., et al. (2019). How stereotypes affect pain. Scientific Reports, 9, 8626

Sescousse, G., Caldú, X., Segura, B., et al. (2013). Processing of primary and secondary rewards: A quantitative meta-analysis and review of human functional neuroimaging studies. Neuroscience \& Biobehavioral Reviews, 37, 681-96

Sharot, T., Guitart-masip, M., Korn, C.W., et al. (2012). How Dopamine enhances an optimism bias in humans. Current Biology, 22, 1477-81

Singmann, H., Bolker, B., Westfall, J., et al. (2018). afex: Analysis of factorial experiments

Slotnick, S.D. (2017). Cluster success: fMRI inferences for spatial extent have acceptable falsepositive rates. Cognitive Neuroscience, 8, 150-55

Smith, E.R., Miller, D. a., Maitner, A.T., et al. (2006). Familiarity can increase stereotyping. Journal of Experimental Social Psychology, 42, 471-78

Stern, C., Rule, N.O. (2018). Physical androgyny and categorization difficulty shape political conservatives' attitudes toward transgender people. Social Psychological and Personality Science, 9, 24-31

Stern, C., West, T. V., Rule, N.O. (2015). Conservatives negatively evaluate counterstereotypical people to maintain a sense of certainty. Proceedings of the National Academy of Sciences, 112, 15337-42

Sullivan, J. (2019). The primacy effect in impression formation: Some replications and extensions. Social Psychological and Personality Science, 10, 432-39

Tamir, D.I., Mitchell, J.P. (2012). Disclosing information about the self is intrinsically 
REWARDING EXPECTATION-CONFIRMATION

rewarding. Proceedings of the National Academy of Sciences, 109, 8038-43

Tamir, D.I., Thornton, M.A. (2018). Modeling the predictive social mind. Trends in Cognitive Sciences, 22, 201-12

Tay, L., Tan, K., Diener, E., et al. (2013). Social relations, health behaviors, and health outcomes: A survey and synthesis. Applied Psychology: Health and Well-Being, 5, 28-78

Theriault, J.E., Young, L., Barrett, L.F. (2020). The sense of should: A biologically-based framework for modeling social pressure. Physics of Life Reviews

Tibboel, H., Houwer, J. De, Bockstaele, B. Van (2015). Implicit measures of "wanting" and "liking" in humans. Neuroscience and Biobehavioral Reviews, 57, 350-64

Tricomi, E., Fiez, J. a (2008). Feedback signals in the caudate reflect goal achievement on a declarative memory task. NeuroImage, 41, 1154-67

Ullsperger, M., von Cramon, D.Y. (2003). Error monitoring using external feedback: Specific roles of the habenular complex, the reward system, and the cingulate motor area revealed by functional magnetic resonance imaging. Journal of Neuroscience, 23, 4308-14

Uusberg, A., Suri, G., Dweck, C.S., et al. (2019). Motivation: A valuation systems perspective. In: M. Neta, I. J. Haas (eds). Emotion in the mind and body. Nebraska symposium on motivation. Vol. 66. Springer, Cham, p. 161-92.

Welborn, B.L., Hong, Y., Ratner, K.G. (2020). Exposure to negative stereotypes influences representations of monetary incentives in the nucleus accumbens. Social Cognitive and Affective Neuroscience, 261-71

Wu, H., Luo, Y., Feng, C. (2016). Neural signatures of social conformity: A coordinate-based activation likelihood estimation meta-analysis of functional brain imaging studies. Neuroscience and Biobehavioral Reviews, 71, 101-11

Wyer, N.A. (2010). You never get a second chance to make a first (implicit) impression: The role of elaboration in the formation and revision of implicit impressions. Social Cognition, 28, $1-19$

Yon, D., Lange, F.P. De, Press, C. (2019). The predictive brain as a stubborn scientist. Trends in Cognitive Sciences, 23, 6-8 
bioRxiv preprint doi: https://doi.org/10.1101/2020.07.19.210757; this version posted April 28, 2021. The copyright holder for this preprint (which

was not certified by peer review) is the author/funder, who has granted bioRxiv a license to display the preprint in perpetuity. It is made available under aCC-BY-NC-ND 4.0 International license.

REWARDING EXPECTATION-CONFIRMATION

\section{Acknowledgements}

2 This work was partially supported by the Israeli Science Foundation (No. 79/18, to N.R.).

3 N.R was supported by Yad Ha'Nadiv (Rothschild) Foundation and the Mind, Brain and Behavior

4 interfaculty program at Harvard University. Parts of this work were conducted at the Harvard

5 Center for Brain Science, which is supported by the NIH Shared Instrumentation Grant Program

6 (No. S10OD020039). We thank Kirstan Brodie for her assistance with data collection for Study

73.

8 
6 Supplementary Materials for

7

8 Confirmation of interpersonal expectations is intrinsically rewarding

9

10 Niv Reggev, Anoushka Chowdhary and Jason P. Mitchell, Harvard University.

11

12 Corresponding author: Niv Reggev

13 Email: reggevn@,bgu.ac.il

14

15

16 Supplementary Materials include:

17

18

Supplementary text

19

Figures $\mathrm{S} 1$ to $\mathrm{S} 4$

20

Tables S1 to S6

21

SI References

22 
REWARDING EXPECTATION-CONFIRMATION

\section{Supplementary Materials: Materials and Methods}

2 Below we provide a detailed description of all the materials and methods used including all

3 measures and data exclusions.

4

\section{Participants}

Studies 1 and 3. Twenty-eight individuals participated in Study 1 (mean age: 21.85, S.D.: 2.95, range: 18-30, 21 females, 15 Caucasian, 4 Hispanic, 4 mixed, 3 Asian, 2 African American) and 30 individuals participated in Study 3 (mean age: 22.37, S.D.: 2.62, range: 18-30, 17 females, 14 Caucasian, 7 Asian, 4 African American, 3 mixed, 1 Hispanic, 1 did not selfidentify). Participants were recruited from Harvard University and its surroundings using Harvard's Psychology Study Pool website. Additional participants were excluded due to technical issues ( 1 participant from Study 3), lack of response to more than $20 \%$ of trials (2 participants from each study) or excessive movement (more than $1 \mathrm{~mm}$ - half-width of the acquired voxel size) in more than one functional run in the scanner (1 participant in Study 1, 3 participants in Study 3). All participants were healthy, right-handed, native English speakers with normal or corrected-to-normal vision and no history of neurological or psychiatric conditions. Participants were compensated with $\$ 65$ in Study 1 and $\$ 55$ in Study 3. We determined supplemental compensation (up to \$30) based on participants' performance in the monetary incentive delay task (see below). Pilot versions of the imaging tasks were conducted outside the scanner to ensure the functionality of the task.

Studies 2 and 4. Three-hundred-ninety-six individuals from Amazon Mechanical Turk completed Study 2 (in Study 2a, 198 out of 216 individuals who started the study; in Study 2b, 198 out of 223 individuals). Study 2a was conducted in March 2018, and Study 2b was 
REWARDING EXPECTATION-CONFIRMATION

1 conducted in April 2018. Four-hundred-seventy individuals from Prolific Academic completed

2 Studies 4a and 4b in January 2019 (235 in each study; a total of 503 participants started the

3 study). All participants were 18 years old or older, had an approval rate of $95 \%$ or higher, held a

4 US nationality and participated only in one of the studies. In addition, participants from Amazon

5 Mechanical Turk were required to have completed at least 100 tasks to be eligible for Study 2.

6 The final sample size we report in the main text incorporates the following pre-registered

7 exclusion criteria for participants who (1) answered incorrectly at least two of the manipulation

8 or attention checks, (2) completed the survey in more than 20 minutes or less than 2.5 standard

9 deviations below the sample mean duration, (3) failed to answer more than $15 \%$ of the survey,

(4) provided similar ratings (on the 0-100 scale) on all trials; specifically, participants whose

11 standard variation of the rating was 2 standard deviations below the sample mean standard

12 deviation (not applied in Study 2a), (5) provided an identical response in all 2AFC trials (applied

13 only in Study 4) and (6) indicated in their debriefing that they had understood the goal of the task

14 and had acted per this understanding at any point during the task. Participants in all studies were

15 similarly distributed on gender (Study 2a: 51.72\% males, 45.98\% females; Study 2b: 50.3\%

16 males, 48.52\% females; Study 4a: 51.32\% males, 46.56\% females; Study 4b: 41.86\% males,

$1756.98 \%$ females; across studies $1 \%-3 \%$ of participants self-identified as gender-nonconforming

18 or other identification), age (Study 2a: Mean [S.D.]: 37.47 [11.75]; Study 2b: 35.13 [10.04];

19 Study 4a: 31.22 [10.32]; Study 4b: 31.99 [10.97]) and ethnicity (Study 2a: 78.16\%

20 White/European American; Study 2b: 74.56\% White/European American; Study 4a: 69.84\%

21 White/European American; Study 4b: 69.19\% White/European American). Study 4 measured

22 political orientation on a 1-9 scale (see below). We observed no differences on this measure

23 between Study 4a and Study 4b (Study 4a: 3.79 [2.13], Study 4b: 3.45 [1.96]). 
REWARDING EXPECTATION-CONFIRMATION

\section{Stimuli}

All studies included face-statement pairs. We selected faces from the 10k US Adult Faces Database (a large-scale database of natural face photographs of the U.S. adult population (Bainbridge et al., 2013)). The current investigation focused on Caucasian faces to avoid intrusion of racial or intersectional stereotypes. We further restricted the faces to be moderately memorable $(0.4-0.6$ hit rate in the $10 \mathrm{k}$ database, computed over an average of 81.7 people per photo) and excluded faces with any kind of distinguishable accessories (e.g. hats, big necklaces, etc.). This resulted in a total of 204 faces, 102 per gender. Three additional photos per gender were used in the practice sessions. All face pictures had neutral to mildly positive expressions. We resized all pictures to 240 by 256 pixels and presented them in color on a gray background (see Fig S1). For Studies 3 and 4 we also included images portraying the faces of Barack Obama and Donald Trump (a single image per leader). These images were taken from open access sources and cropped to be identical in dimensions to the rest of the face stimuli.

We generated gender-stereotype-relevant statements in the form of individual preference, trait, behavior or profession (e.g., "Loves taking risks", "Doesn't cry", "Swears a lot”, "Is a truck driver", etc.; see https:/osf.io/tgja3/?view_only=d849bad1b606474f80c1a3e40e740875). We piloted the verbal statements in a two-phase procedure using non-overlapping groups of participants that did not participate in the reported studies. In the first session, 23 participants rated 160 gender-related statements generated by the authors based on various sources (e.g., Prentice and Carranza, 2002). Participants saw each statement once and indicated how typical the characteristic was for a specific gender on a visual scale of 0 (= "very untypical") to 100 (= "very typical"; the scale had no other tick marks). Each participant rated each statement either for men or for women, never for both, randomly determined per participant. Participants were 
REWARDING EXPECTATION-CONFIRMATION

1 instructed to base their ratings on how they thought the average person would respond. Based on

2 the ratings from this first phase, we selected 136 gender-related statements (68 per gender) for

3 which the average rating was at least 65 for one of the genders and less than 35 for the other

4 gender. In a second session of the pilot testing, we verified the stereotypicality of these

5 statements with a total of 78 participants who used the same rating procedure to rate the selected

6136 statements and an additional 68 gender-neutral statements (e.g., "Exercises regularly",

7 “Thinks positively", "Is a TV reporter"). The statements included in the studies contained 2-9

8 words (mean: 4.69, S.D: 1.44; no difference between experimental conditions, $p>0.2$ ) and 9-45

9 characters (mean: 26.68, S.D.: 7.69; $p>0.18$ ).

We utilized a similar procedure for leader-relevant statements. First, we generated 160 statements based on common knowledge about the selected leaders. We constructed the

12 statements such that a statement consistent with knowledge about one leader would violate

13 knowledge about the other leader. We piloted these statements with 243 Amazon Mechanical

14 Turk participants. Each participant saw a randomly selected subset of 40 or 60 statements and

15 rated them on two scales: "how likely is the statement to be attributed to Barack Obama" and

16 "how likely is the statement to be attributed to Donald Trump" on a visual scale of 0 (= "very

17 unlikely") to 100 (= "very likely"). Participants were instructed to base their ratings on how they

18 thought the average person would respond. Each statement had an average of 81.75 raters (S.D.:

19 6.23; range: 67-100). We selected the 120 statements that differed the most between ratings for

20 the two leaders. Overall, the statements contained 2-9 words (mean: 4.65, S.D: 1.52; no

21 difference between experimental conditions, $p>0.5$ ) and 11-45 characters (mean: 28.33, S.D.:

$22 \quad 8.43 ; p>0.5)$. 
REWARDING EXPECTATION-CONFIRMATION

\section{Behavioral procedure}

2 Studies 1 and 3. The impression formation task included 204 face-statement pairs in Study 1 and

3240 face-statement pairs in Study 3. To create stereotype-consistent and stereotype-violating

4 pairs, we yoked half of the 136 stereotypical statements (120 statements in Study 3) with faces

5 from the gender corresponding to the stereotype and the other half with faces from the

mismatching gender (yoking of statements was randomized across participants; e.g., the statement "Doesn't cry" could be paired with a male face for one participant and with a female face for another participant to create a stereotype-consistent or a stereotype-violating pair, respectively). Gender-neutral statements (presented only in Study 1; 68 statements) were randomly and evenly yoked with male and female faces. We randomized the specific face identity paired with each statement across participants. We used a similar procedure to create leader-specific pairs (60 statements per leader), with the exception that a single photo was used per leader.

Impression Formation Task. Each trial in the Impression Formation task (see Fig S1) started with a statement (describing a neutral, stereotypically male or stereotypically female characteristic in Study 1; stereotypically male, stereotypically female, Obama-specific or Trumpspecific in Study 3) presented for 1.5 seconds. Then, a face joined the statement to form a facestatement pair that was either consistent or inconsistent (or, in Study 1, neutral) with gender stereotypes or (in Study 3) person-specific knowledge. The pair appeared on screen for 4 seconds for a total of 5.5 seconds per trial in Study 1, and 3.5 seconds for a total of 5 seconds in Study 3 . Each trial ended with a 0.5 -second fixation crosshair. For each pair, participants used their left hand to indicate how likely the presented target was to be described by the specific characteristic 
REWARDING EXPECTATION-CONFIRMATION

1 using a 4-point scale (1- 'very unlikely'; 4 -'very likely'). Participants were to provide a response

2 while the pair appeared on screen.

3 Each of four functional runs included 51 (in Study 1) or 60 (in Study 3) unique face-

4 statement pairs (17 per condition in Study 1, 15 per condition in Study 3). In Study 3 we

5 presented statements in mini-blocks by knowledge domain (stereotypes versus person-specific),

62 blocks per type per run; each mini-block contained 15 trials. Order of the mini-blocks was

7 randomly determined within each run with a limitation that consecutive blocks never displayed

8 the same type of content. To optimize estimation of the event-related fMRI response, we

9 intermixed conditions in a pseudorandom order and separated trials by a variable interstimulus

10 interval (Study1: 0-9 seconds, mean: 3.03, S.D.: 2.25; Study 3: 0-7 seconds, mean: 1.24, S.D:

11 1.84). We used OptSeq2 (Dale, 1999) to generate sequences optimized for the efficiency of a 3-

12 conditions design for a first-order counterbalanced event sequence in Study 1 and for the

13 efficiency of the (expectancy-consistent versus expectancy-violating) contrast for a first-order

14 counterbalanced event sequence in Study 3. Of these sequences, we selected 6 sequences that

15 contained no more than 5 consecutive events of the same condition (separate sequences were

16 generated and selected per Study). We randomly assigned (with replacement) an event sequence

17 for each functional run to avoid spurious results attributable to differences between conditions in

18 one specific event sequence (Mumford et al., 2014). Within conditions, trials were presented in

19 random order. To facilitate familiarization with the task, participants completed a brief practice

20 session before entering the MRI machine. This practice session included six statement-face pairs

21 in Study 1 and 12 pairs in Study 3; the stimuli used in the practice were not used in any other

22 phase of the experiment. 
REWARDING EXPECTATION-CONFIRMATION

Monetary Incentive Delay (MID) Task. After completing the impression formation task, participants in Studies 1 and 3 completed the Monetary-Incentive Delay (MID) task (Knutson et al., 2000) to allow us to localize brain regions associated with the processing of rewarding stimuli in a non-social context. Participants were not informed about this task before its execution to prevent them from forming an association between the main task and reward processing.

The MID task included a series of trials in which participants attempted to respond, via a button press, to a briefly presented target (a white rectangle) (see Fig S1B). Each trial started with a cue (a blue circle or a green circle) that was presented for 0.5 seconds. The green circle predicted a modest monetary reward $(\$ 1)$ upon a successful response to the target, whereas the blue circle predicted no reward. Nevertheless, participants were instructed to respond to both cue types. Cues were followed by a delay interval randomly varying in duration between 2 and 2.5 seconds. The target was then briefly presented for a duration varied between 130 and 350 milliseconds. Duration varied as a function of the participants' performance. Specifically, we implemented a 2-down 1-up staircase procedure to create a level of difficulty that would allow participants to successfully respond to the target on two-thirds of the trials. This algorithm succeeded; on average, participants were rewarded on approximately 20 of the 30 trials (Study 1 mean: 20.26; Study 3: 20.21). At the end of each trial, participants saw the amount of money they had earned on that trial along with the total amount they had earned during the task up to that point (presented for 0.5 seconds). The task included 45 trials (with 30 green cue trials). We added participants' gains in this task to their overall compensation.

Memory Test. Once outside the scanner, participants completed a surprise associative memory task that will be reported elsewhere (Reggev \& Mitchell, in preparation). Briefly, none 
REWARDING EXPECTATION-CONFIRMATION

1 of the results reported in the current manuscript were affected by including memory in the

2 analyses.

Additional measures. Next, participants completed several individual differences and

5 explicit attitudes scales measuring beliefs about sexism (Ambivalent Sexism Inventory - ASI)

6 (Glick and Fiske, 1996), social dominance orientation (SDO) (Ho et al., 2015), motivation to

7 control sexism (MCS) (Klonis et al., 2005) and need for cognitive closure (NFC) (Kruglanski et

8 al., 1993). Order of the scales was randomized between participants. We included these scales to

9 facilitate future individual differences analyses. Individual differences scores were not used in

10 the current manuscript in any of the analyses due to insufficient power and are reported solely for

11 full disclosure's sake.

Finally, participants in Study 1 indicated the extent to which they thought the different statements presented during the impression formation task were associated with women and men using the procedure used for piloting the statements. We presented each statement with the gender to which it was yoked in the impression formation task. Participants had up to 10 seconds per trial and were told that they should base their judgments on their own beliefs about men and women, rather than on what the "average" person in the population thinks.

22 suspected a memory test. Lastly, we paid and fully debriefed them. 
REWARDING EXPECTATION-CONFIRMATION

Images were collected with a 3T Siemens Prisma scanner system (Siemens Medical

4 Systems, Erlangen, Germany) using a 64-channel radiofrequency head coil. Stimuli were

5 projected onto a screen at the end of the magnet bore that participants viewed via a mirror mounted on the head coil. Stimulus presentation was controlled by PsychoPy v1.84.2(Peirce,

7 2007) running under Windows 7. Prior to entering the scanner participants were extensively briefed by one of the authors about potential movements that can occur in the scanner and ways to mitigate them. Participants were then set up in the scanner, head first and supine in the scanner bore, with a response box in their left hand. Foam cushions were placed within the head coil to minimize head movements. First, high-resolution anatomical images were acquired using a T1weighted 3D MPRAGE sequence $(\mathrm{TR}=2200 \mathrm{msec}, \mathrm{TI}=1100 \mathrm{msec}$, acquisition matrix $=256 \times$ $256 \times 176$, flip angle $=7$, voxel size $=1 \times 1 \times 1 \mathrm{~mm}^{3}$ ). Second, a fieldmap was acquired in the

14 same plane as the functional images (see below) to correct for inhomogeneities in the magnetic field (Cusack and Papadakis, 2002). Next, whole-brain functional images were collected using a simultaneous multi-slice (multiband) T2*-weighted gradient echo sequence, sensitive to BOLD

17 contrast, developed at the Center for Magnetic Resonance Research (CMRR) at University of Minnesota (Feinberg et al., 2010; Moeller et al., 2010; Xu et al., 2013) $(\mathrm{TR}=2000 \mathrm{msec}, \mathrm{TE}=$

$1930 \mathrm{msec}$, voxel size $=2 \times 2 \times 2 \mathrm{~mm}^{3}, 75$ slices auto-aligned to -25 degrees of the AC-PC line, image matrix $=104 \times 104, \mathrm{FOV}=208 * 208 \mathrm{~mm}^{2}$, flip angle $=75^{\circ}$, GRAPPA acceleration factor

$21=2$, multiband factor $=3$, phase encoding direction $=\mathrm{A}->\mathrm{P})$. After a brief practice run

22 (identical in content to the practice session completed before entering the scanner), participants completed four impression formation task runs consisting of 229 volumes each in Study 1 and 
REWARDING EXPECTATION-CONFIRMATION

1245 volumes each in Study 3; all runs were complemented by two additional dummy scans and

2 an initial period of approximately $26 \mathrm{~s}$ dedicated to references for the GRAPPA procedure. The

3 first four volumes from each run (i.e., in addition to dummy scans) were discarded to ensure T1

4 equilibrium. The last 5 volumes from each run always included a crosshair fixation to ensure the

5 appropriate estimation of the hemodynamic function for the last events in the run. Finally,

6 participants completed the MID task in a single run consisting of 110 volumes using identical

7 parameters to those mentioned above.

$8 \quad$ Imaging analysis

We processed and analyzed the fMRI data using SPM12 version 6225 (Wellcome

Department of Cognitive Neurology, London, UK) on a 2015b MATLAB platform (Mathworks,

Papadakis, 2002), realigned to the first image to correct for head movement using a $2^{\text {nd }}$ degree B-

spline interpolation, unwarped to account for residual movement-related variance using a $4^{\text {th }}$

degree B-spline interpolation and co-registered with each participant's anatomical data. Then,

17 based on the ICBM152 brain template (Montreal Neurological Institute). Normalized data were

19 addition to the GLM models reported in the main text, in Study 1 we also examined a model in

21 binning approach. Specifically, this additional model included two regressors - one for trials

22 including a woman's face and another for trials including a man's face. We included a separate 
REWARDING EXPECTATION-CONFIRMATION

1 statement included in that trial based on our pilot ratings. For example, the statement "Can lift

2 heavy things" was rated as related more to men than to women in our pilot studies with a 28-

3 points difference on the $0-100$ scale. Consequently, the parametric modulation value was 0.28

4 for trials in which this statement was presented with a man's face, and -0.28 for trials in which

5 this statement was presented with a woman's face. Similar to the models reported in the main

6 text, in this additional model we convolved events with a canonical hemodynamic response

7 function and its temporal derivative and included additional covariates of no interest (session

8 mean, no response trials, six motion parameters, and their temporal derivative).

\section{Regions of interest (ROIs)}

We used two complementary approaches to localize regions involved in the processing of rewards. For independently defined ROIs, we defined 8-mm spheres around peak coordinates drawn from a recent meta-analysis (Bartra et al., 2013). Specifically, we utilized the peaks of the region identified as supporting the processing of both monetary and primary incentives: bilateral ventral striatum $(x=-6, y=10, z=-6$ and $x=10, y=12, z=-6)$.

To functionally locate these regions, we examined the MID task to identify voxels that responded more to rewarded trials (i.e., trials in which participants successfully responded to the target) than to no-reward trials (i.e., trials in which no reward was available). Whole-brain corrected clusters (using the procedure described in the main text) were defined as independent ROIs.

As we had no prediction about laterality of the hypothesized effects, we collapsed across hemispheres to create a single ROI. We extracted and averaged parameter estimates across 
REWARDING EXPECTATION-CONFIRMATION

1 voxels and analyzed them with planned contrasts in a repeated-measures ANOVA context using

$2 \mathrm{p}<0.05$ as a threshold.

Studies 2 and 4. In each trial, participants chose one of two decks of cards (see Fig S2). We instructed participants to choose based on their preferences regarding the information they had available for each trial. Participants had two sources of information to rely on. First, each deck was associated with a small monetary payoff (ranging from $\$ 0.03$ to $\$ 0.09$ in 2 cents increments). Participants were told that a subset of their choices ( 5 trials in Study 2, 7 trials in Study 4) would be added to their final compensation for the study. Payoff amounts for each choice varied across trials (and were occasionally equal). Payoff disparities (i.e., the differences in monetary values associated with each deck) followed a quasi-gaussian distribution, such that the most extreme disparities ( 6 cents in favor of one deck or the other) always appeared the least,

12 twice (Study 2) or thrice (Study 4) for each participant. As disparities grew smaller they gradually became more frequent, with the zero disparity trials (i.e., equivalent monetary values deck was associated with a specific label ("Typical" versus "Atypical” in Study 2, "Common" versus "Uncommon" in Study 4) that determined the content presented when that deck is

17 selected (stereotypical or counter-stereotypical targets in Study 2, knowledge-consistent or knowledge-violating targets in Study 4). After making their selection, participants saw a facestatement pair corresponding to their choice. For example, if a participant in Study 2 selected the

20 "Typical" deck, they would be presented with a stereotypical target (e.g., in Study 2a a male

21 associated with the statement "CEO of a big company"). Participants then indicated how likely

22 that target was to possess that characteristic on a visual scale of 0 (= "Not at all likely") to 100 (= 23 "Very likely"; the scale had no other tick marks). The location of the specific labels (right deck 
REWARDING EXPECTATION-CONFIRMATION

1 versus left deck) was counterbalanced between participants. Study 2a included only faces of men, Study $2 \mathrm{~b}$ included only faces of women, Study $4 \mathrm{a}$ included only the face of Barack Obama and Study $4 b$ included only the face of Donald Trump.

All studies included a demo trial, 4 practice trials, and 25 deck selection trials (32 trials in Study 4). We also included several catch trials to detect if participants were responding without considering the statement presented. The catch trials prompted the participants to slide the bar to the right tick mark or to the left tick mark. Participants had up to $4 \mathrm{~s}$ to select a card and up to $5 \mathrm{~s}$ to rate an individual. Participants that did not respond fast enough to more than $20 \%$ of the trials got their survey terminated midway through the task. The specific amounts associated with each trial and the face-statement pairs presented per trial were randomized. Following these trials, participants were presented with 4 final manipulation-check trials in which they were asked to

12 select the card with the higher value.

After completing the main task, participants responded to the individual difference scales mentioned above - ASI, SDO, MCP, and NFC. Order of the scales was randomized between participants. No significant correlations between Point of Subjective Equivalence (PSE) and the individual scores on these scales were consistently detected across studies. Finally, participants

17 supplied demographic information (including age, self-reported gender identity, self-reported race with multiple answers enabled and whether they were born in the US). Study 4 also probed 19 participants' political affiliation (as in Study 3), how much they liked Barack Obama and how much they liked Donald Trump on two separate 0-100 scales. Then, we probed for participants'

21 intuitions about the goal of the task and fully debriefed them. 
REWARDING EXPECTATION-CONFIRMATION

\section{Supplementary Materials Results}

\section{Behavioral analyses: Neuroimaging studies}

Table S1 presents the summaries of participants' ratings and reaction times in the impression formation task in Study 1. We analyzed rating data with mixed models as implemented in the lme4 package version 1.1-14 (Bates et al., 2014) and the 'ordinal' package version 2018.4-19 (Christensen, 2018) for $\mathrm{R}$ version 3.4.2 (R Core Team, 2017). As the behavioral data obtained in the impression formation task were ordinal, we analyzed them using cumulative link mixed models (CLMM) with the logit link. To avoid the transformation of raw reaction time data, we used generalized linear models (gLMMs) with the inverse Gaussian identity link (Lo and Andrews, 2015). We included random effects for the intercepts for participants and statements, as well as by-participant random slopes for the fixed effect of stereotypicality. Trials that elicited no response $(<1.5 \%$ of all trials; no difference between conditions) were excluded from all analyses.

To examine whether our stereotype-consistent and stereotype-violating targets were indeed perceived differently by our participants in Study 1, we tested the effect of our a-priori categorization on behavioral ratings in a CLMM. Stereotypicality was dummy coded with stereotype-neutral trials as the intercept and behavioral ratings were centered on 0 . Overall stereotypicality affected ratings, as indicated by leave-one-out model comparison, comparing our model to an intercept only model $\left(\chi^{2}{ }_{(2)}=44.45, p<0.001\right)$. The manipulation worked as anticipated: Stereotype-consistent targets received higher ratings than stereotype-neutral targets $(\beta \pm S E=0.42 \pm 0.14, Z=2.99, p=0.003)$, whereas stereotype-violating targets received lower ratings $(\beta \pm S E=-1.22 \pm 0.15, Z=-8.31, p<0.001)$. 
REWARDING EXPECTATION-CONFIRMATION

$$
\text { Stereotypicality did not have a main effect on reaction time for the behavioral ratings }
$$
$\left(\chi^{2}(2)=0.35, p>0.8\right)$. However, reaction time did vary by the interaction of stereotypicality and behavioral ratings, as indicated by comparing a model with an interaction term to a model without it, $\left.\chi^{2}(2)=133.88, p<0.001\right)$; participants were slower to provide responses that were not in line with our a-priori definitions (e.g., indicating that a woman is very likely to be a firefighter or saying that a man is very unlikely to be a CEO); see Table S1 for full descriptive results.

Behavioral results in Study 3 generally replicated the behavioral results we obtained in Study 1 (see Table S3). The outcome of the expectation (whether the target were consistent with or violated the expectation) significantly affected participants' ratings $\left(\chi_{(1)}^{2}=73.61, p<0.001\right)$. Domain (stereotype-based or person-specific-based knowledge) also affected participants' ratings $\left(\chi_{(1)}^{2}=27.58, p<0.001\right)$. Interestingly, participants distributed their expectation-based responses differently between the domains (outcome by domain interaction: $\chi^{2}{ }_{(1)}=862.52, p<$ 0.001). Participants used more extreme outcome-congruent ratings for person-specific expectations compared to stereotype-based expectations (see Table S3).

Similar to Study 1, participants' reaction time did not differ between expectationconsistent or expectation-violating trials $(t=-0.29, p=0.77)$, nor between person-specific or stereotype-based expectations $(t=1.89, p=0.059)$. Comparable to Study 1 , we observed a significant interaction between outcome and behavioral ratings $(t=-15.11, p<0.001)$, an interaction that was qualified by a 3 -way interaction with domain $(t=6.36, p<0.001)$. To interpret this interaction, we analyzed responses separately for the two knowledge domains. In both knowledge domains, participants responded faster when their responses were in line with our a-priori definitions $(t=-9.72$ and $t=-13.81$ for stereotype- and person-specific-based expectations, respectively; $p$ 's $<0.001$ ). 
REWARDING EXPECTATION-CONFIRMATION

\section{Neuroimaging}

In Study 3, in addition to the main findings (see Fig 1 and Table S4), the design allowed us to compare the effects of expectation-consistency with different specific targets, namely, men, women, Trump or Obama. Analyzing activity in the NAcc in a 2 (expectation result) X 2 (content domain) X 2 (specific target) ANOVA yielded, in addition to the main effect of expectation consistency $\left(F_{(1,29)}=21.41, p<0.0001, \eta^{2}{ }_{p}=0.42\right.$ [0.19-0.58], a main effect of content domain $\left(F_{(1,29)}=4.56, p=0.04, \eta^{2}{ }_{p}=0.14[0.003-0.32]\right.$; all other effects $\left.\mathrm{p}>0.1\right)$ such that gender-related trials were associated with increased activity. To complement the findings, we conducted a whole-brain interaction analysis to examine whether any neural regions responded differently to the confirmation or violation of expectations between specific targets. Given the different experimental context between the two content domains, we first examined the interaction of expectations and specific targets within each content domain separately. This analysis yielded 3 regions ( $\mathrm{p}<0.05$, FWE-corrected; Table S5 and Figure S3), including the left inferior frontal gyrus (LIFG) and left superior temporal gyrus (LSTG), in which consistency with expectations yielded more activity than their violation only when the statements pertained to Trump (LIFG results: $F_{(1,114.24)}=40.12, p<0.0001, \eta^{2}{ }_{p}=0.26[0.15-0.36]$ ) and not to any of the other targets (triple interaction: $F_{(1,29)}=33.32, p<0.0001, \eta_{p}^{2}=0.53[0.30-0.66$; similar patterns were observed in LSTG]. Disambiguating this triple interaction, we verified the interaction between expectation results and specific targets for leaders: $F_{(1,29)}=42.73, p<0.0001, \eta^{2}{ }_{p}=0.6$ [0.37-0.71]; the parallel interaction within gender content was not significant: $F_{(1,29)}=0.55, p>$ $\left.0.4, \eta_{p}^{2}=0.02[0-0.03]\right)$. Notably, no main effect of expectation results was observed in these regions (all $p$ 's $>0.05$ ). Together, these findings suggest that the consistency with expectations 
REWARDING EXPECTATION-CONFIRMATION

1 pertaining to Donald Trump evokes an additional process which is not triggered for confirmation

2 of other types of expectations.

3 Behavioral analysis: Online studies

4 In addition to the analyses reported in the main manuscript (for raw distribution data, see Table

5 S6), in Study 4 we also performed an exploratory pre-registered analysis to examine the

6 relationship between PSEs and support for the specific leader. To that end, we collected from

7 each participant how much they liked Barack Obama and how much they liked Donald Trump

8 on two separate $0-100$ scales. Unsurprisingly for online data collection, our participants

9 demonstrated a skewed preference toward Barack Obama (mean Obama liking for participants in

10 Study 4a: 71.89, S.D. $=28.68$; mean Trump liking for participants in Study 4b: 17.1, S.D. $=$

11 27.33). We correlated these data with PSEs for the corresponding leader in each study. As can be

12 seen in Figure S4, the data are extremely skewed, with many participants indicating the

13 maximum liking rating for Obama and the minimum liking rating for Trump. As such, we do not

14 provide inferential statistics as these data violate the statistical assumptions. Descriptively, we

15 can see a small positive slope between PSE and liking for each leader. These descriptive trends

16 can be taken to cautiously hint that the more one likes a leader, the more they would be willing to

17 forgo money to see information consistent with the expectation from that leader. 
REWARDING EXPECTATION-CONFIRMATION

\section{Supplementary Materials References}

Bainbridge, W.A., Isola, P., Oliva, A. (2013). The intrinsic memorability of face photographs. Journal of Experimental Psychology: General, 142, 1323-34

Bartra, O., McGuire, J.T., Kable, J.W. (2013). The valuation system: A coordinate-based meta-analysis of BOLD fMRI experiments examining neural correlates of subjective value. NeuroImage, 76, 412-27

Bates, D.M., Maechler, M., Bolker, B., et al. (2014). lme4: Linear mixed-effects models using Eigen and S4

Christensen, R.H.B. (2018). ordinal---Regression Models for Ordinal Data

Cusack, R., Papadakis, N. (2002). New robust 3-D phase unwrapping algorithms: Application to magnetic field mapping and undistorting echoplanar images. NeuroImage, 16, 754-64

Dale, A.M. (1999). Optimal experimental design for event-related fMRI. Human Brain Mapping, 8, 10914

Feinberg, D.A., Moeller, S., Smith, S.M., et al. (2010). Multiplexed echo planar imaging for sub-second whole brain FMRI and fast diffusion imaging. PloS one, 5, e15710

Glick, P., Fiske, S.T. (1996). The Ambivalent Sexism Inventory: Differentiating hostile and benevolent sexism. Journal of Personality and Social Psychology, 70, 491-512

Ho, A.K., Sidanius, J., Kteily, N., et al. (2015). The nature of social dominance orientation: Theorizing and measuring preferences for intergroup inequality using the new $\mathrm{SDO}_{7}$ scale. Journal of Personality and Social Psychology, 109, 1003-28

Klonis, S.C., Plant, E.A., Devine, P.G. (2005). Internal and external motivation to respond without sexism. Personality and Social Psychology Bulletin, 31, 1237-49

Knutson, B., Westdorp, A., Kaiser, E., et al. (2000). FMRI visualization of brain activity during a monetary incentive delay task. NeuroImage, 12, 20-27

Kruglanski, A.W., Webster, D.M., Klem, A. (1993). Motivated resistance and openness to persuasion in the presence or absence of prior information. Journal of Personality and Social Psychology, 65, $861-76$

Lo, S., Andrews, S. (2015). To transform or not to transform : Using Generalized Linear Mixed Models to analyse reaction time data. Frontiers in Psychology, 6, 1-16

Moeller, S., Yacoub, E., Olman, C.A., et al. (2010). Multiband multislice GE-EPI at 7 tesla, with 16-fold acceleration using partial parallel imaging with application to high spatial and temporal whole-brain fMRI. Magnetic Resonance in Medicine, 63, 1144-53

Mumford, J.A., Davis, T., Poldrack, R.A. (2014). The impact of study design on pattern estimation for single-trial multivariate pattern analysis. NeuroImage, 103, 130-38

Peirce, J.W. (2007). PsychoPy-Psychophysics software in Python. Journal of Neuroscience Methods, 162, $8-13$

Prentice, D.A., Carranza, E. (2002). What women and men should be, shouldn't be, are allowed to be, and don't have to be: the contents of prescriptive gender stereotypes. Psychology of Women Quarterly, 26, 269-81

Xu, J., Moeller, S., Auerbach, E.J., et al. (2013). Evaluation of slice accelerations using multiband echo 
bioRxiv preprint doi: https://doi.org/10.1101/2020.07.19.210757; this version posted April 28, 2021. The copyright holder for this preprint (which

was not certified by peer review) is the author/funder, who has granted bioRxiv a license to display the preprint in perpetuity. It is made available under aCC-BY-NC-ND 4.0 International license.

\section{REWARDING EXPECTATION-CONFIRMATION}

1 planar imaging at 3 T. Neuroimage, 83, 991-1001

2

3

4 


\section{REWARDING EXPECTATION-CONFIRMATION}

\section{Supplementary Materials Figures}

(A)
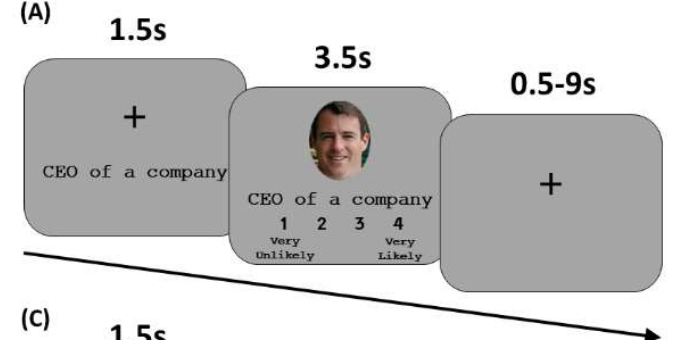

(c)

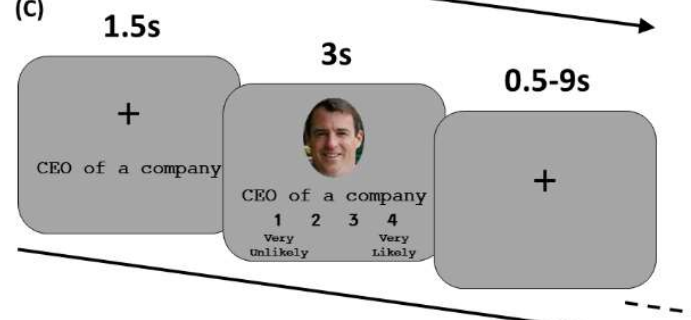

(B)

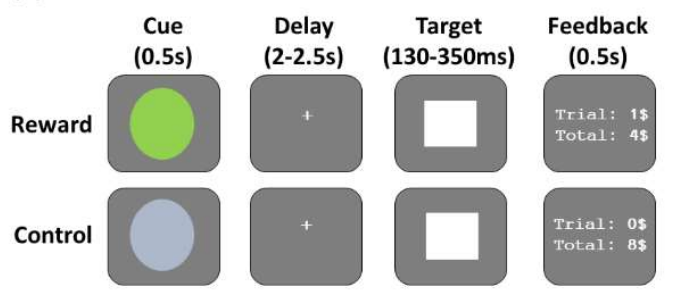

$1.5 \mathrm{~s}$

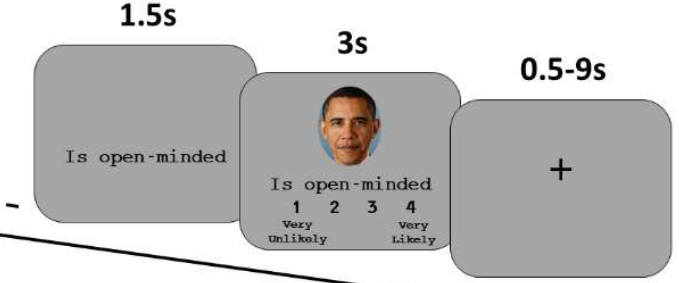

$3 \quad$ Fig S1. Experimental designs of Studies 1 and 3. (A) In Study 1, participants saw 204 unique trials. Each started with a gender-relevant or irrelevant statement, followed by a target face consistent with, violating or neutral in respect to the displayed statement. Participants indicated how likely the presented person was to have the characteristic described in the statement on a 1

7 ("very unlikely") to 4 ("very likely") scale. (B) Following the impression formation task, participants completed the monetary incentive delay (MID) task. In each trial, participants saw a cue predicting the outcome of a successful response to the target. A green cue always indicated monetary reward, a blue cue always indicated no reward. Participants saw 30 reward cues and 15 no-reward cues. After a randomly jittered delay a target appeared on screen for a brief duration (determined by a 2-up-1-down staircase procedure). Participants received feedback about their performance in each trial and across the entire task. (C) In Study 3, participants rated 240 trials,

14 including 120 stereotype-related targets and 120 person-specific trials. Each content domain

15 (stereotypes versus person-specific) was presented in separate blocks of 15 consecutive trials per 16 type. 


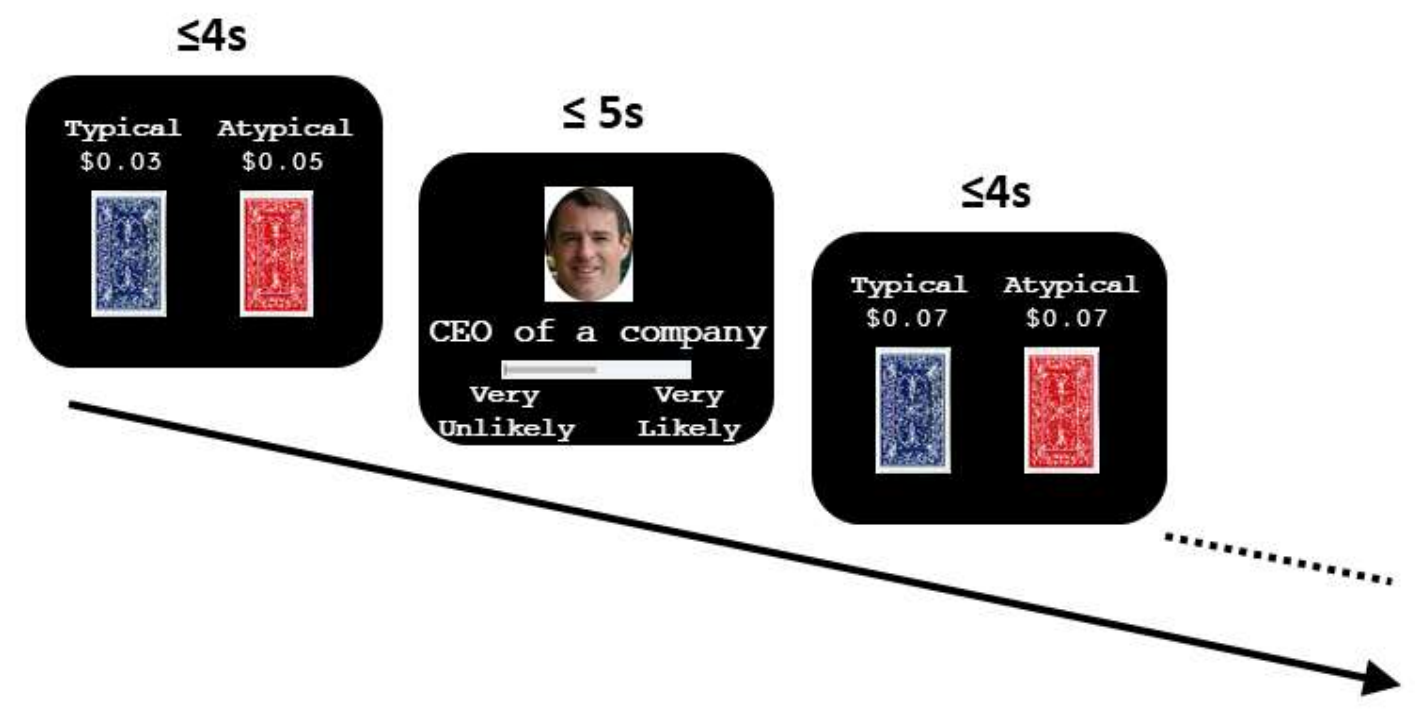

3 Fig S2. Experimental design of Study 2a. Participants chose which target type to rate (typical,

4 denoting stereotype-confirming targets, versus atypical, denoting stereotype-violating targets).

5 Each target type was associated with a variable amount of money. After deciding which target

6 type to rate, participants then rated a target of the chosen type. The design of studies $2 \mathrm{~b}, 4 \mathrm{a}$ and

$7 \quad 4 \mathrm{~b}$ followed this procedure. 
bioRxiv preprint doi: https://doi.org/10.1101/2020.07.19.210757; this version posted April 28, 2021. The copyright holder for this preprint (which was not certified by peer review) is the author/funder, who has granted bioRxiv a license to display the preprint in perpetuity. It is made available under aCC-BY-NC-ND 4.0 International license.

REWARDING EXPECTATION-CONFIRMATION

1

2

A

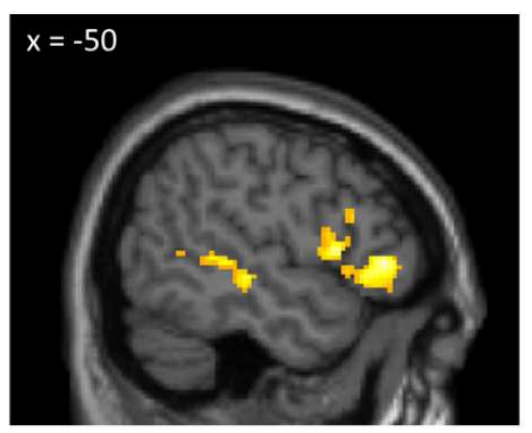

B

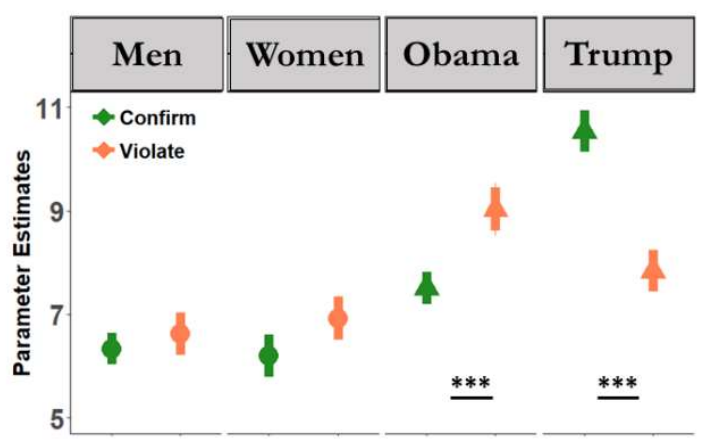

3

$4 \quad$ Fig S3. Neural responses as a function of expectancy-outcome and type of target. (A) results

5 of a whole-brain analysis examining the interaction of outcome and type of target (see main text

6 and Table S5 for details). (B) Parameter estimates drawn from the Left Inferior Frontal Gyrus

7 ROI. 


\section{REWARDING EXPECTATION-CONFIRMATION}

a

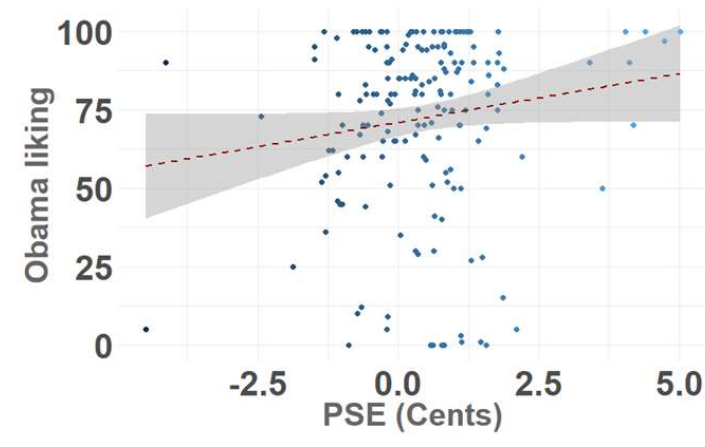

b

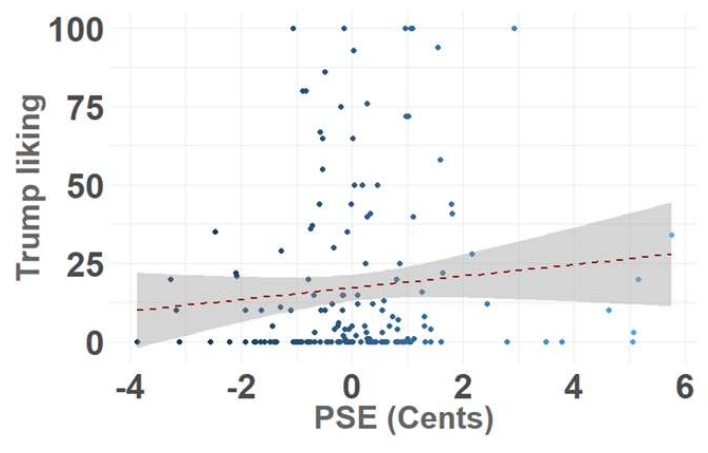

2 Fig S4. The correlations between the subjective value of expectation-consistent information and the

3 liking of a specific leader in Study 4. The subjective value was calculated as the point of subjective

4 equivalence (PSE) per participant, as detailed in the main text. (a) Results from Study 4a in which

5 participants chose between seeing trials with expectation-consistent and expectation-inconsistent

6 information about Barack Obama. (b) Results from Study 4b in which participants made equivalent

7 choices about trials including Donald Trump. We do not provide inferential statistics as these data are

8 heavily skewed. 
1 Table S1. Distribution of participants' ratings and reaction time (RT, in milliseconds) as a

2 function of stereotypicality in the impression formation task in Study 1. Parentheses indicate

3 standard error of the mean.

\begin{tabular}{|c|c|c|c|c|c|}
\hline & Very Likely & \multicolumn{2}{|c|}{ Somewhat Likely Somewhat Unlikely } & Very Unlikely & No Response \\
\hline \multicolumn{6}{|c|}{ Stereotype-confirming (68) } \\
\hline Proportion & $0.27(0.03)$ & $0.39(0.03)$ & $0.23(0.02)$ & $0.09(0.01)$ & $0.01(0.005)$ \\
\hline RT & $1676(28)$ & $1845(27)$ & $2100(30)$ & $1751(54)$ & \\
\hline \multicolumn{6}{|c|}{ Stereotype-neutral (68) } \\
\hline Proportion & $0.18(0.02)$ & $0.42(0.03)$ & $0.26(0.0 .2)$ & $0.12(0.02)$ & $0.01(0.004)$ \\
\hline RT & $1676(34)$ & $1855(31)$ & $2047(35)$ & $1814(69)$ & \\
\hline \multicolumn{6}{|c|}{ Stereotype-violating (68) } \\
\hline Proportion & $0.07(0.01)$ & $0.27(0.02)$ & $0.36(0.02)$ & $0.29(0.02)$ & $0.01(0.005)$ \\
\hline RT & $1828(77)$ & $1946(26)$ & 2015 (31) & $1640(32)$ & \\
\hline
\end{tabular}


1 Table S2. Study 1: Gray matter regions showing differences in activity between stereotypical

2 (stereotype-consistent) and counter-stereotypical (stereotype-violating) targets in model 1 (with

3 no specification of behavioral response; $\mathrm{p}<0.05$, corrected).

$\begin{array}{cccccc}\text { Megion } & \text { MN coordinates } & & & \text { Z value } & \text { \# voxels } \\ & X & Y & Z & \end{array}$

(a) Stereotypical > Counter-Stereotypical

$\begin{array}{lccccc}\text { Nucleus Accumbens } & -2 & 4 & -6 & 4.98 & 30 \\ \text { L Inferior Temporal } & -50 & -56 & -12 & 4.03 & 108 \\ & \text { (b) Counter-Stereotypical }>\text { Stereotypical } & & & \\ & & & & & \\ & 34 & -22 & 58 & 4.38 & 145 \\ \text { R Motor } & 46 & 32 & -10 & 4.07 & 18 \\ \text { R Inferior Frontal } & 8 & 36 & 50 & 3.8 & 50\end{array}$

(c) Parametric Modulation (From Counter-Stereotypical to Stereotypical)

$\begin{array}{lccccc}\text { L inferior Parietal Sulcus } & -30 & -82 & 36 & 4.22 & 17 \\ \text { L Inferior Temporal } & -48 & -58 & -12 & 4.19 & 60 \\ \text { Extrastriate Cortex } & 14 & -84 & -12 & 3.72 & 22 \\ \text { Nucleus Accumbens } & 0 & 6 & -6 & 4.15 & 20 \\ & -8 & 8 & -4 & 3.91 & 13\end{array}$


bioRxiv preprint doi: https://doi.org/10.1101/2020.07.19.210757; this version posted April 28, 2021. The copyright holder for this preprint (which

was not certified by peer review) is the author/funder, who has granted bioRxiv a license to display the preprint in perpetuity. It is made available under aCC-BY-NC-ND 4.0 International license.

REWARDING EXPECTATION-CONFIRMATION

(d) Parametric Modulation (From Stereotypical to Counter-Stereotypical)

$\begin{array}{lccccc}\text { R Motor } & 34 & -20 & 58 & 4.41 & 128 \\ \text { R Medial prefrontal } & 12 & 48 & 12 & 4.33 & 18 \\ \text { R Inferior Parietal } & 58 & -50 & 38 & 3.94 & 18 \\ \text { Dorsomedial Prefrontal } & 8 & 36 & 50 & 3.85 & 16\end{array}$

1 
1 Table S3. Distribution of participants' ratings and reaction time (RT, in milliseconds) as a

2 function of expectation domain and expectation-consistency in the impression formation task in

3 Study 3. Parentheses indicate standard error of the mean.

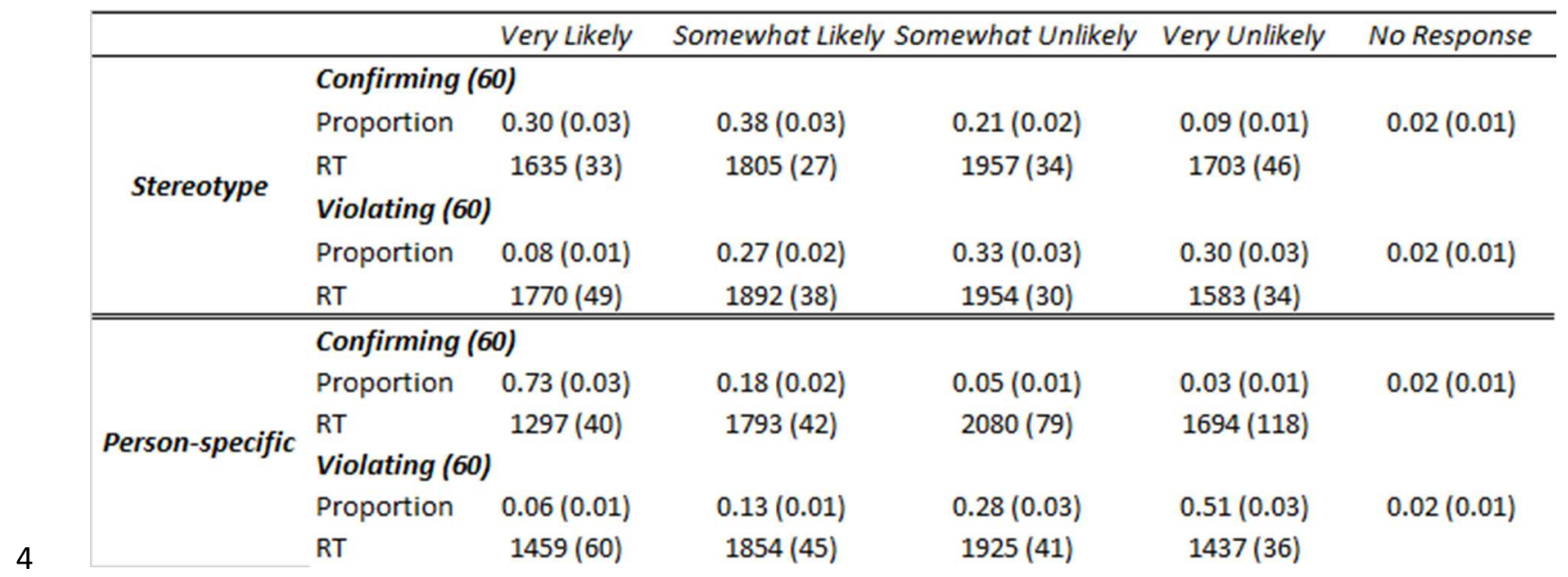




\section{REWARDING EXPECTATION-CONFIRMATION}

1 Table S4. Study 3: Gray matter regions showing differences in activity between expectation-

2 consistent and expectation-violating targets. (a) and (b) portray the results collapsed across

3 content domain, (c) through (f) include the results per content domain ( $\mathrm{p}<0.05$, corrected).

$\begin{array}{cccccc}\text { Megion } & \text { MN coordinates } & & \text { Z value } & \text { \# voxels } \\ & X & Y & Z\end{array}$

(a) Main effect: Confirming > Violating

\begin{tabular}{|c|c|c|c|c|c|}
\hline Extrastriate Cortex & 12 & -80 & -4 & 5.63 & 2800 \\
\hline R Motor & 46 & -14 & 52 & 5.43 & 298 \\
\hline L Ventral Striatum & -12 & 20 & -2 & 4.93 & 89 \\
\hline L Insula & -48 & 4 & 8 & 4.87 & 59 \\
\hline Cerebellum & 10 & -74 & -38 & 4.82 & 56 \\
\hline Cerebellum & -18 & -76 & -44 & 4.58 & 35 \\
\hline L Occipitotemporal Cortex & -44 & -68 & 0 & 4.57 & 463 \\
\hline R Ventral Striatum & 6 & 6 & -8 & 4.52 & 49 \\
\hline R Insula & 36 & 6 & 10 & 4.51 & 40 \\
\hline L Parietal Operculum & -44 & -32 & 20 & 4.34 & 166 \\
\hline Occipital Cortex & 24 & -96 & 20 & 4.29 & 266 \\
\hline Posterior Cingulate & -2 & -34 & 44 & 4.26 & 240 \\
\hline R Fusiform Gyrus & 48 & -42 & -16 & 4.25 & 57 \\
\hline
\end{tabular}




\section{REWARDING EXPECTATION-CONFIRMATION}

\begin{tabular}{|c|c|c|c|c|c|}
\hline R Occipitotemporal Cortex & 54 & -60 & 0 & 4.19 & 221 \\
\hline L Superior Temporal & -66 & -36 & 20 & 4.08 & 62 \\
\hline L Insula & -36 & -12 & 14 & 4.06 & 42 \\
\hline L Parahippocampus & -24 & -40 & -6 & 4.06 & 50 \\
\hline L Inferior Frontal & -42 & 38 & 12 & 4.01 & 34 \\
\hline Precuneus & -16 & -62 & 16 & 3.98 & 103 \\
\hline Ventromedial Prefrontal & 6 & 42 & -16 & 3.86 & 28 \\
\hline L Motor & -50 & -16 & 54 & 3.77 & 112 \\
\hline L Temporal Pole & -48 & 14 & -14 & 3.72 & 20 \\
\hline R Orbitofrontal & 26 & 38 & -18 & 3.69 & 26 \\
\hline R Inferior Frontal & 52 & 8 & -4 & 3.64 & \\
\hline
\end{tabular}

(b) Main effect: Violating > Confirming

$\begin{array}{lccccc}\text { Dorsomedial Prefrontal } & 12 & 34 & 52 & 4.22 & 23 \\ \text { R Motor } & 36 & -24 & 54 & 3.99 & 50 \\ \text { Dorsomedial Prefrontal } & -8 & 42 & 50 & 3.92 & 62 \\ \text { L Middle Frontal } & -38 & 20 & 46 & 3.88 & 32\end{array}$

(c) Gender: Confirming > Violating 


\section{REWARDING EXPECTATION-CONFIRMATION}

$\begin{array}{lccccc}\text { Extrastriate Cortex } & 10 & -78 & -6 & 4.48 & 146 \\ \text { R Occipitotemporal Cortex } & 54 & -62 & 2 & 3.80 & 47 \\ \text { Ventral Striatum } & 4 & 10 & -10 & 3.78 & 21 \\ \text { L Motor } & 52 & -12 & 54 & 3.66 & 64 \\ \text { R Lateral Occipital } & 30 & -84 & 38 & 3.55 & 28\end{array}$

(d) Gender: Violating > Confirming

Dorsomedial Prefrontal

L Middle Frontal
12

$-34$

20

$52 \quad 3.92$

33

19

46

47

64

28

(e) Leaders: Confirming > Violating

$\begin{array}{lccccc}\text { Extrastriate Cortex } & 8 & -76 & -6 & 5.56 & 1854 \\ \text { R Motor } & 48 & -14 & 52 & 5.42 & 204 \\ \text { Posterior Cingualte } & -8 & -40 & 54 & 4.34 & 57 \\ \text { L Parietal Operculum } & -42 & -36 & 26 & 4.31 & 248 \\ \text { R Insula } & 36 & 6 & 10 & 4.23 & 24 \\ \text { L Temporal Pole } & -50 & 12 & -12 & 4.19 & 80 \\ \text { Cerebellum } & & & & & \\ & 24 & -66 & -44 & 4.18 & 24 \\ \text { R Supramarginal gyrus } & 50 & -36 & 8 & 4.06 & 50\end{array}$


bioRxiv preprint doi: https://doi.org/10.1101/2020.07.19.210757; this version posted April 28, 2021. The copyright holder for this preprint (which

was not certified by peer review) is the author/funder, who has granted bioRxiv a license to display the preprint in perpetuity. It is made available under aCC-BY-NC-ND 4.0 International license.

REWARDING EXPECTATION-CONFIRMATION

L Inferior Frontal / Insula

L Occipitotemporal Cortex

Cuneus

R Fusiform Gyrus

Cerebellum

L Occipitotemporal Cortex

Precuneus

L Inferior Frontal

Precuneus

Ventral Striatum

Anterior Cingualte

R Inferior Frontal / Insula

L Motor

$-48$

$-44$

$-2$

48

$-44$

8

$-74$

$-48$

$-58$

$-14 \quad-66$

$28 \quad 3.71$

55

$-60$

6

$10 \quad 3.68$

22

$\begin{array}{ll}-14 & -78\end{array}$

$42 \quad 3.62$

74

$-10$

20

$-2 \quad 3.57$

21

$-2$

14

$\begin{array}{ll}32 & 3.49\end{array}$

31

50

4

$-2 \quad 3.48$

22

$-50$

$-16$

$54 \quad 3.45$

22

(f) Leaders: Violating > Confirming

$\begin{array}{lccccc}\text { R Motor } & 40 & -24 & 60 & 4.17 & 90 \\ \text { Dorsomedial Prefrontal } & -8 & 42 & 50 & 3.77 & 22\end{array}$


1 Table S5. Study 3: Results of a set of two whole-brain analyses examining the interactive effects

2 of expectation-consistency and specific target, done separately for gender and leaders. $(\mathrm{p}<0.05$,

3 corrected).

Region

MNI coordinates

$X$

(a) Gender: Confirmation effect in men > Confirmation effect in women

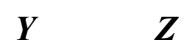

Z value \#voxels

(b) Gender: Confirmation effect in women > Confirmation effect in men

None

(c) Leaders: Confirmation effect in Obama > Confirmation effect in Trump

None

(d) Leaders: Confirmation effect in Trump > Confirmation effect in Obama

$\begin{array}{lccccc}\text { Cuneus } & 12 & -88 & 24 & 5.16 & 435 \\ \text { L Inferior Frontal } & -50 & 34 & 2 & 4.83 & 473 \\ \text { L Superior Temporal } & -62 & -36 & 4 & 4.32 & 352 \\ \text { Extrastriate Cortex } & -6 & -80 & 6 & 3.67 & 75\end{array}$




\section{REWARDING EXPECTATION-CONFIRMATION}

1 Table S6. Distribution of proportions of trials in Studies 2 and 4 in which participants chose to

2 see an expectation-confirming target. Data are presented as a function of the difference in

3 monetary value between the two decks of cards.

\begin{tabular}{ccccc}
\hline $\begin{array}{c}\text { Monetary } \\
\text { Difference }\end{array}$ & $\mathbf{N}$ & $\begin{array}{c}\text { \% Consistent } \\
\text { Chosen }\end{array}$ & S.D. & $\boldsymbol{C l}$ \\
\hline \multicolumn{5}{c}{ Study 2a } \\
& \multicolumn{5}{c}{} \\
-6 & 173 & 0.124 & 0.318 & 0.048 \\
-4 & 174 & 0.149 & 0.301 & 0.045 \\
-2 & 174 & 0.187 & 0.268 & 0.040 \\
0 & 174 & 0.577 & 0.246 & 0.037 \\
2 & 174 & 0.843 & 0.253 & 0.038 \\
4 & 174 & 0.885 & 0.273 & 0.041 \\
6 & 171 & 0.919 & 0.270 & 0.041
\end{tabular}

Study $2 a$

$\begin{array}{lllll}-6 & 167 & 0.084 & 0.274 & 0.042 \\ -4 & 169 & 0.145 & 0.284 & 0.043 \\ -2 & 169 & 0.198 & 0.238 & 0.036 \\ 0 & 169 & 0.573 & 0.273 & 0.041 \\ 2 & 169 & 0.848 & 0.217 & 0.033 \\ 4 & 169 & 0.906 & 0.229 & 0.035 \\ 6 & 166 & 0.902 & 0.294 & 0.045\end{array}$

Study 4a

$\begin{array}{lllll}-6 & 187 & 0.070 & 0.185 & 0.027 \\ -4 & 189 & 0.110 & 0.177 & 0.025 \\ -2 & 189 & 0.148 & 0.204 & 0.029 \\ 0 & 189 & 0.603 & 0.253 & 0.036 \\ 2 & 189 & 0.895 & 0.172 & 0.025 \\ 4 & 189 & 0.910 & 0.182 & 0.026 \\ 6 & 189 & 0.938 & 0.179 & 0.026\end{array}$

\section{Study 4b}

$\begin{array}{rllll}-6 & 172 & 0.089 & 0.196 & 0.030 \\ -4 & 172 & 0.107 & 0.190 & 0.029 \\ -2 & 172 & 0.156 & 0.192 & 0.029 \\ 0 & 172 & 0.491 & 0.247 & 0.037 \\ 2 & 172 & 0.876 & 0.179 & 0.027 \\ 4 & 172 & 0.911 & 0.163 & 0.024\end{array}$


bioRxiv preprint doi: https://doi.org/10.1101/2020.07.19.210757; this version posted April 28, 2021. The copyright holder for this preprint (which

was not certified by peer review) is the author/funder, who has granted bioRxiv a license to display the preprint in perpetuity. It is made available under aCC-BY-NC-ND 4.0 International license.

REWARDING EXPECTATION-CONFIRMATION

$\begin{array}{lllll}6 & 172 & 0.904 & 0.226 & 0.034\end{array}$

1 